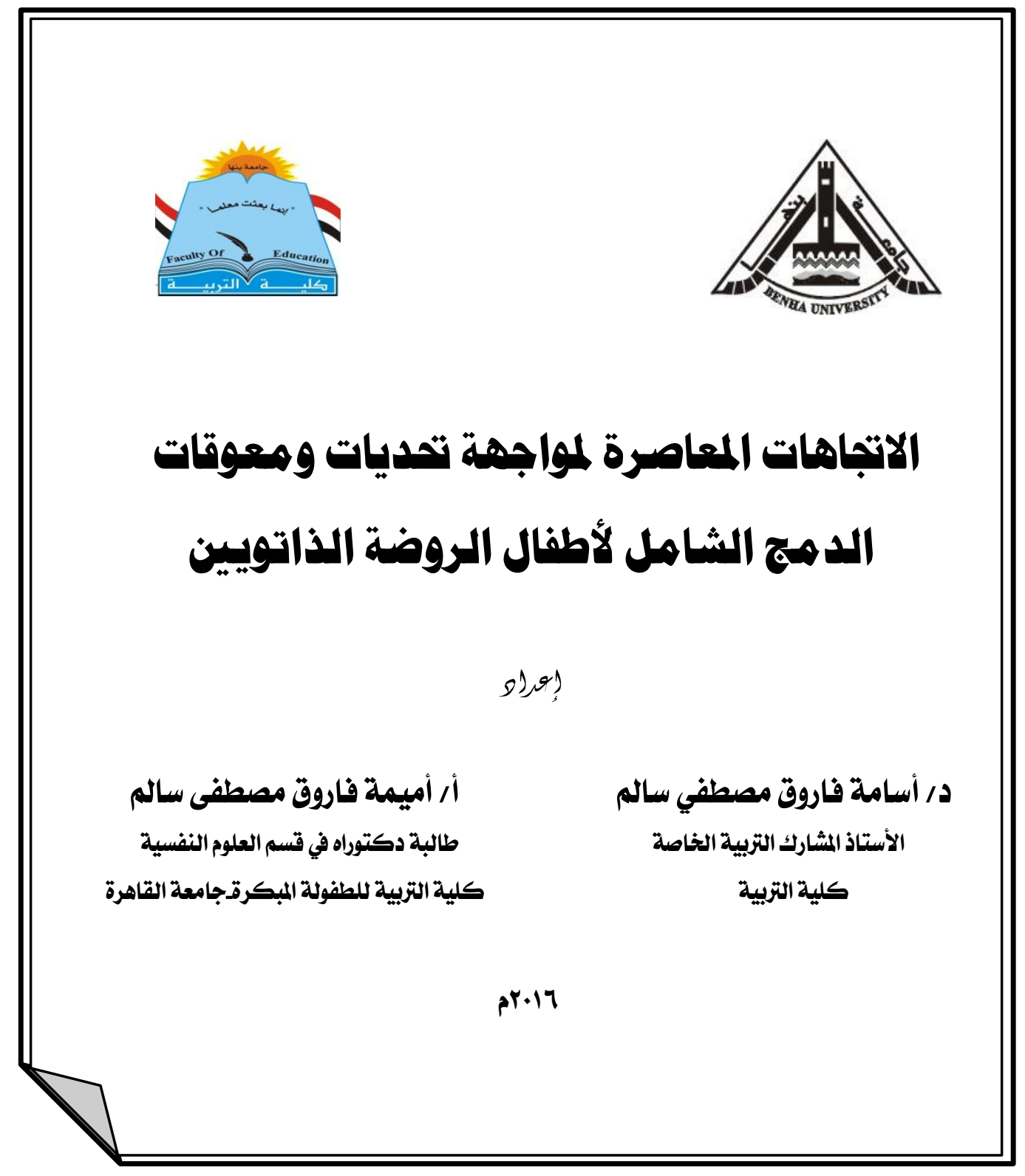




\title{
الاتجاهات المعاصرة لمواجهة تحديات ومعوقات الدمج الشامل لأطفال الروضة الذاتويين
}

\author{
9) (9)
}

أر أميمة فاروق مصطفى سالم

طالبة دكتوراه في قسم العلوم النفسية

كلية التربية للطفولة البكرقة فيكامعة القاهرة
د/ أسامة فاروق مصطفي سالم

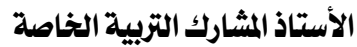

كلية التربية

\section{ملخص البحـــ}

هدف البحث الحالى الى أهية التخخل المبكر وضرورة دمج اطفال الروضـــة

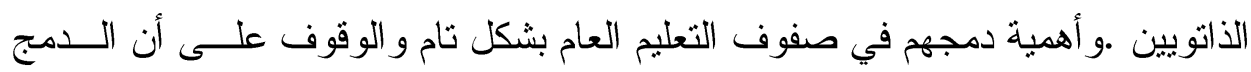

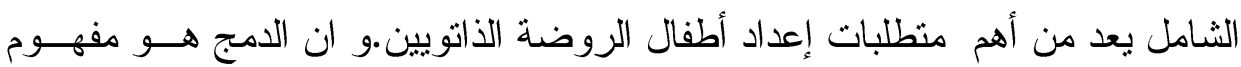

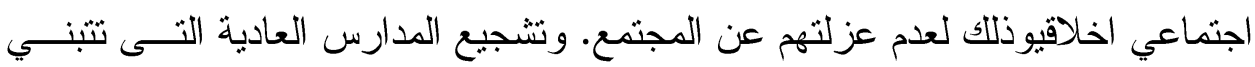

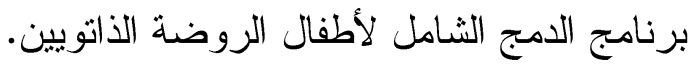

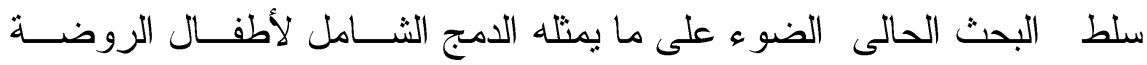

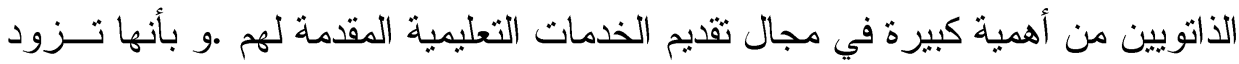

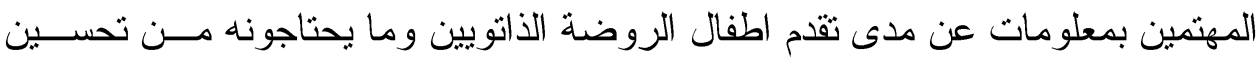

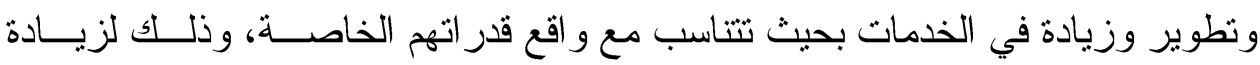

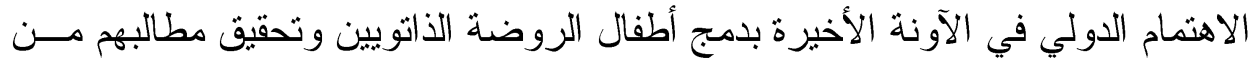

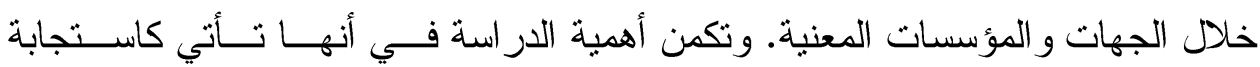

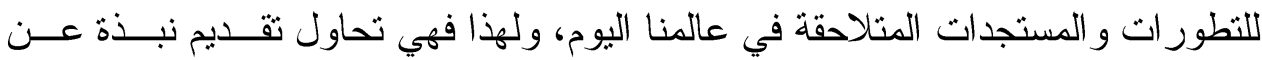

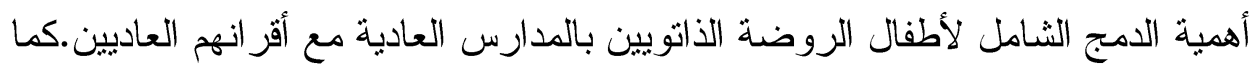

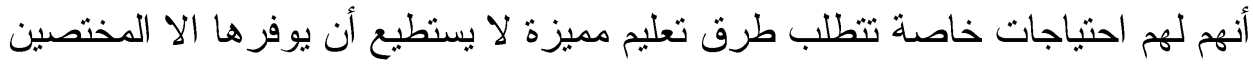

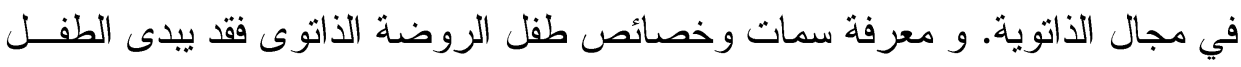

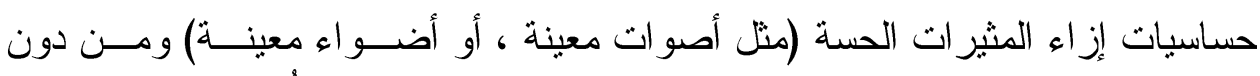

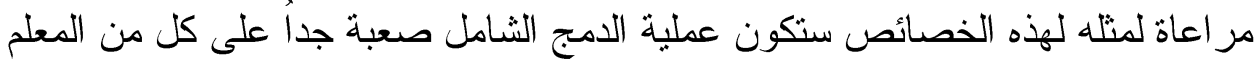

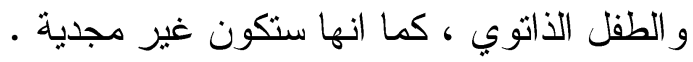

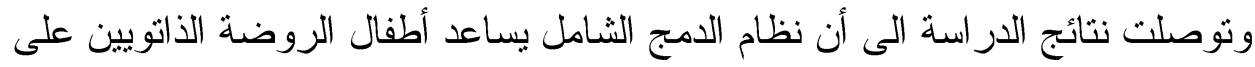

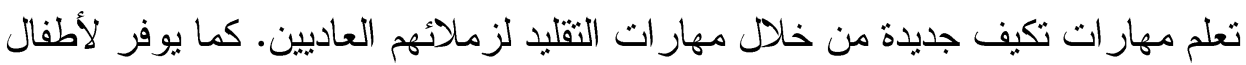




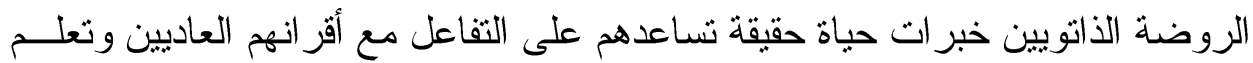
مهار ات اجتماعية وتو اصلية جديدة. و يوفر التكاليف الاقتصادية بعدم فتح مر اكز للتربية

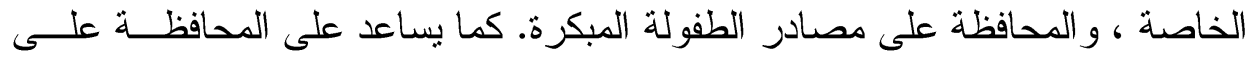

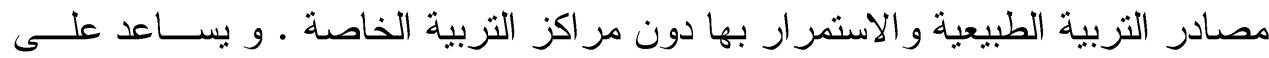
تبادل الخبرات بين أولياء أمور الاطفال العاديين و غير العاديين. الكلمات المفتاحية :الدمج الثامل - الذاتوية- اطفال الروضة

أن النظرة الى المعاق تختلف من مجتمع الى آخر ، ومن زمن الى آخر ، تبعاً

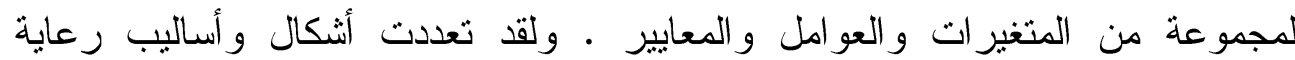

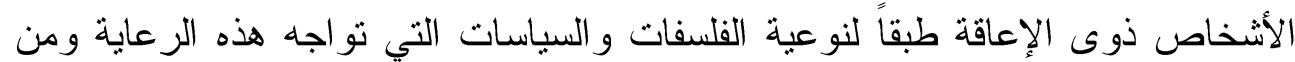

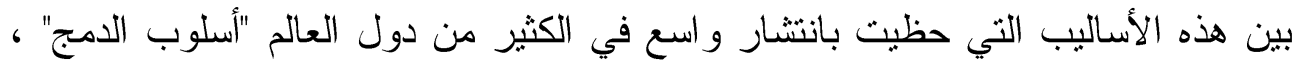

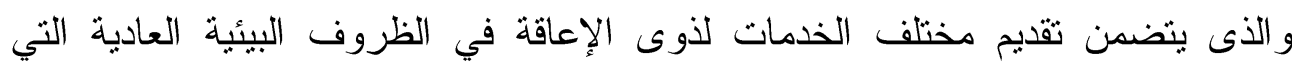

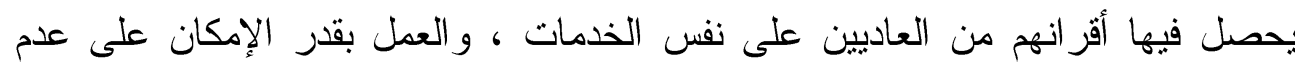
عزلهم في أماكن منفصلة.

وقد بدأ الاهنمام بالثربية الخاصة للمعوقين وذوى الاحتباجات الخاصة مع بدايات

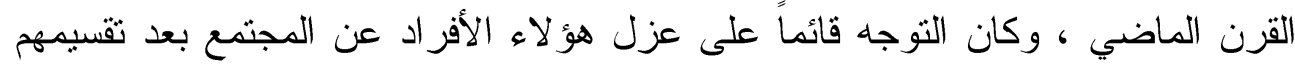
إلى فئات كل حسب إعاقته ، في مدارس ومعاهد التربية الخاصة مع تقديم بر امج تأهيلية خاصة بهم.

فلقد مارست كثير من الدول عزل الأفراد من ذوى الإعاقة في مؤسساتهم لفترة

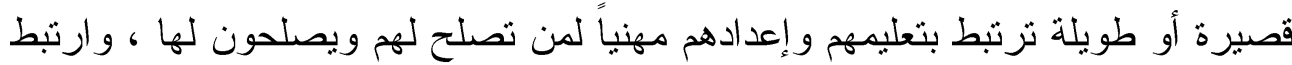

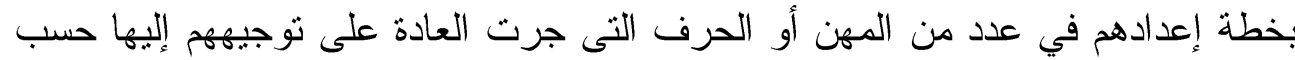

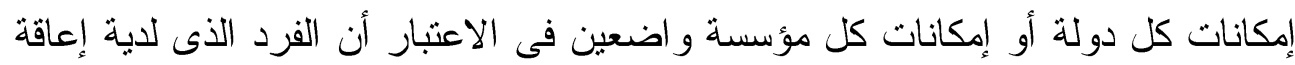

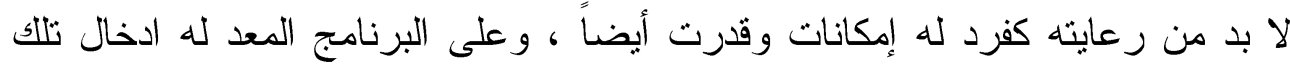

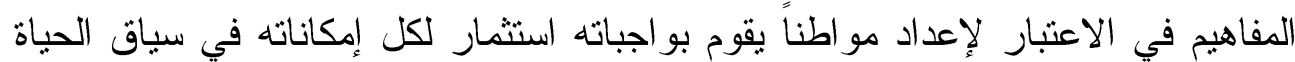
الاجتماعية ، وأن يكون الفرد الذى لديه إعاقة هو عمله و انتاجه وكيانه جزء هن من الخطة الإنه

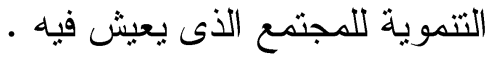




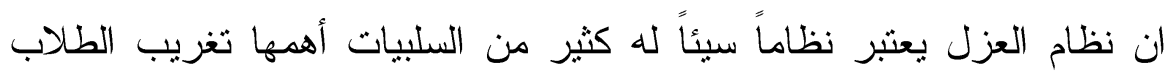

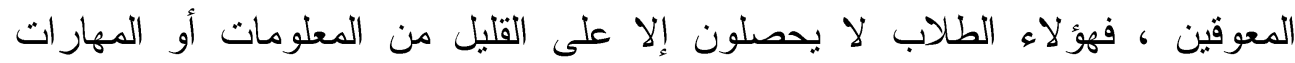

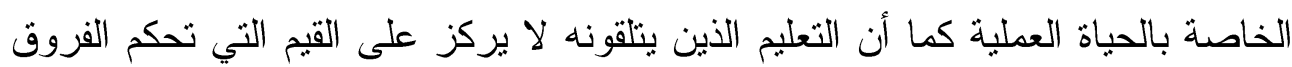

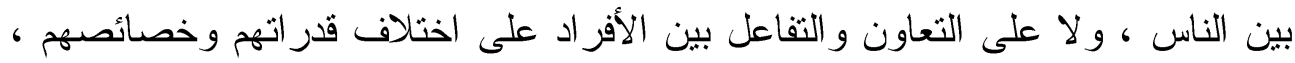

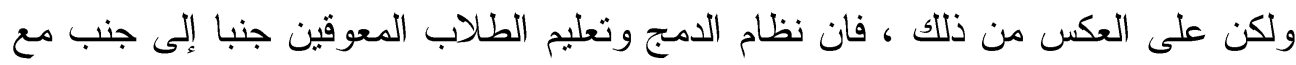

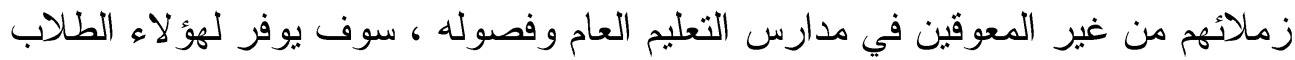

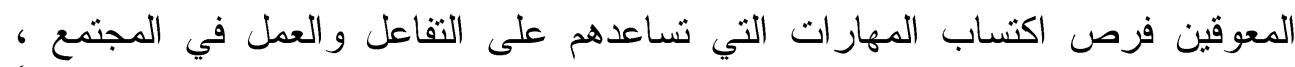

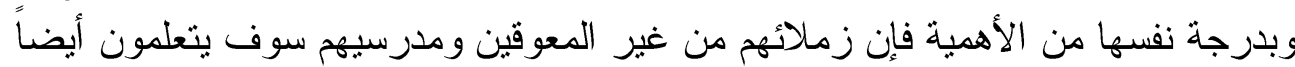
كيفية التعامل معهم.

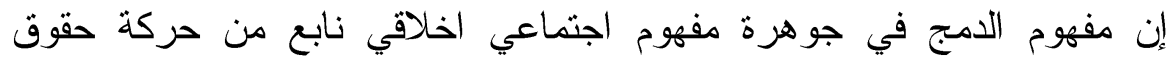
الانسان ضد التصنيف و العزل لأى فرد بسبب إعاقته . إلى جانب تزمايد ايد الاتجاهات

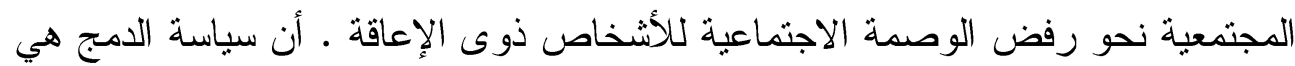

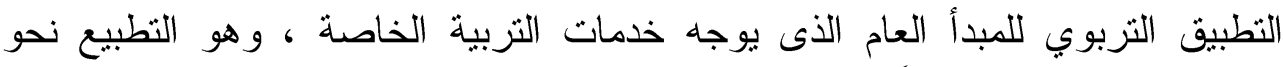
العادية في أقل البيئات تقيداً.

يعبر مبدأ الدمج عن دمج ذوي الإعاقات في صفوف التعليم العام بشكل ثام ،

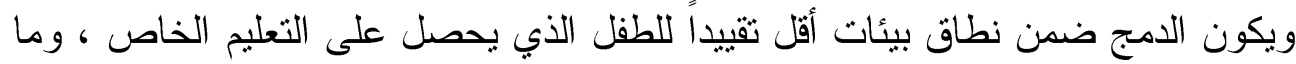
يرثبط به من خدمات ، وذللك بناء على احتياجات ذلك الطفل.

وتعتبر قضية الدمج لذوى الاحتباجات الخاصة قضية هامة جداً ، ونحن نسعي

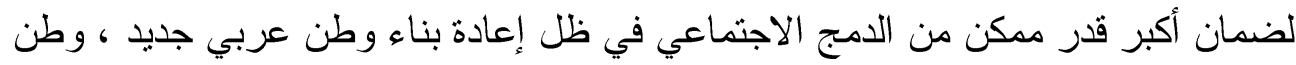

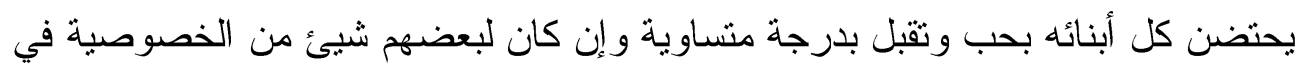
·عض الأمور

ضرورة دمج أطفال الروضة الذاتويين في صفوف التعليم العام بشكل تام وذلك لعدم عزلتهم عن المجتمع. الوقوف على أن الدمج الثشامل يعد من أهم متطلبات إعداد أطفال الروضة الذاتوبين. 


$$
\text { الوقوف على أهمية ان مفهوم الامج اجتماعي اخلاقي. }
$$

تشجيع المدارس العادية التى تتبني برنامج الدمج الشامل لأطفال الروضة الذاتوبين.

تكمن أهمية الدراسة الحالية في أنها تسليط الضوء من خلال محاورها على ما بمثلك الدمج الثامل لأطفال الروضة الذاتوبين من أهمية كبيرة في مجال تقديم

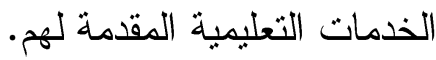

تكمن أهمية الدر اسة الحالية بأنها ثزود المرتمين بمعلومات عن مدى ثقدم اطفال

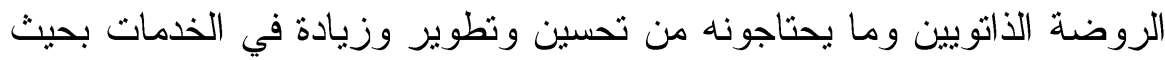

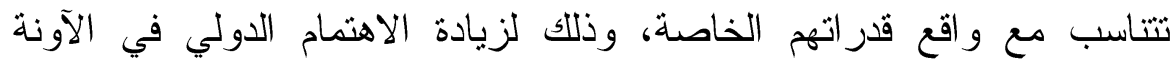
الأخيرة بدمج أطفال الروضة الذاتويين وتحقيق مطالبهم من خلال الجهات و المؤسسات المعنية.

تكمن أهمية الدر اسة في أنها تأتبكاستجابة للنطور ات و المستجدات المتلاحقة في عالمنا اليوم، ولهذا فهي تحاول تقديم نبذة عن أهمية الدمج الشامل لأطفال الروضة الذاتويينبالمدارس العادية مع أقر انهم العاديين. تكمن أهمية الدر اسة فى أن أطفال الروضة الذاتويين لهم احتباجات خاصة تثطلب طرق تعليم مميزة لا يستطيع أن يوفرها الا المختصين في مجال الذاتوية..

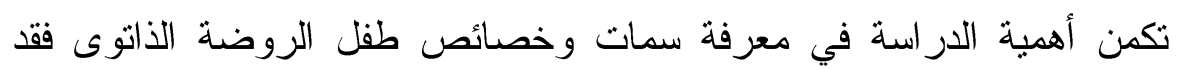

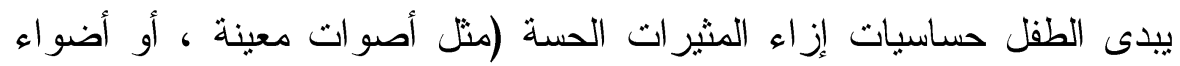

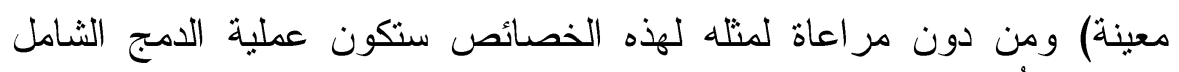

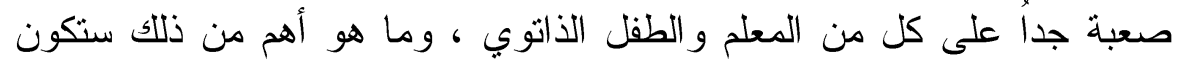

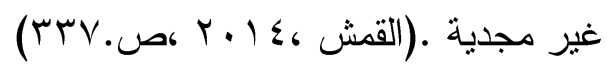




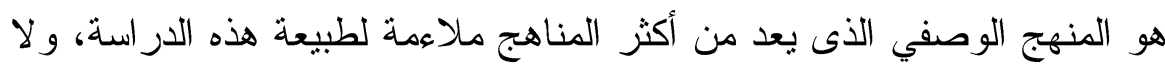

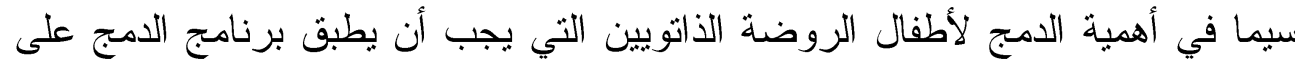

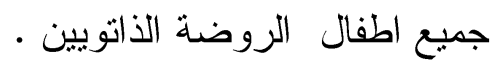
وسوف يقوم الباحثان بعرض المحاور التالية:

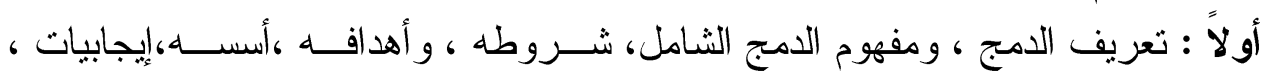

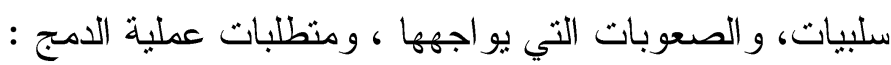

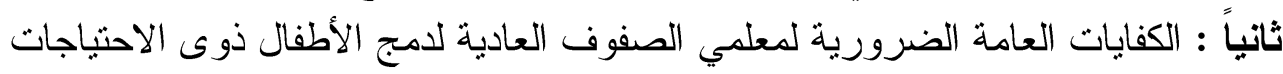
الخاصة. ثالثاً: خصائص و إعداد مدارس الدمج الشاملالأطفال الذاتويين:

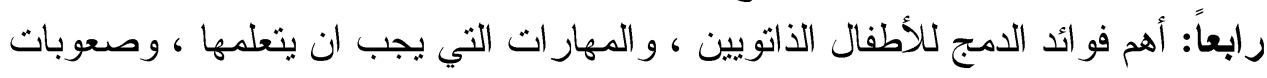
دمجهم: المحور الأول: تعريف الامج ، ومفهوم الامج الشامل، شروطه ، وأهدافه ،أسسه

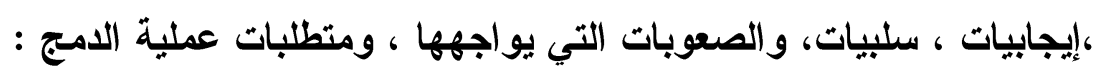

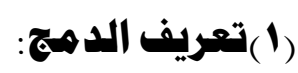

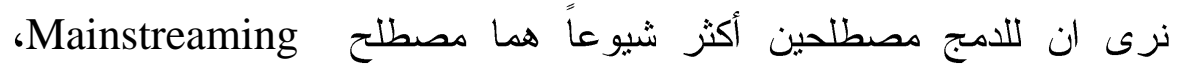

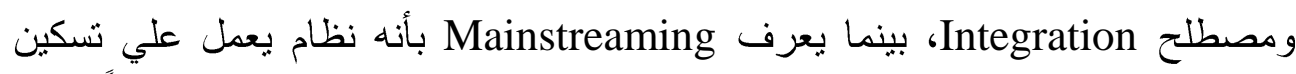
الأطفال المعاقين و الإبقاء عليهم في حجرات الدراسة العادية كلما كان ذلك ممكناً ولكي بلكي ينفصل هذا المصطلح على العزل يجب أن يشنمل على العناصر التالية: كيتعلم الأطفال مع أقر انهم العاديين في الفصول العادية لأقصي درجة ممكنة وفي ضوء خصائص كل طفل.

-إن مسئولية تعليم الطفل هى مسئولية مشتركة بين مدرس التعليم العام و التزبية الخاصة . - الا يتم تصنيف الأطفال على أنهم معاقون.(الشناوى ، (1997)

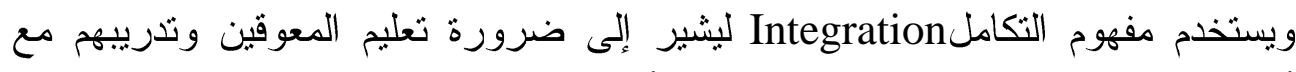
أقرانهم العاديين ، ويعتبر هذا المصطلح أكثر ملاعمة ، حيث يتضمن عملية تكيف 
الجوانب الاجنماعية والعضوية والمهنية للمعوقين مع المجتمع مع مر اعاة الحاجات

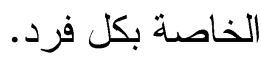

و الدمج هو أن يعيش المعوق عيشة آمنة في كل مكان بتو اجد فيه ، وأن يشعر

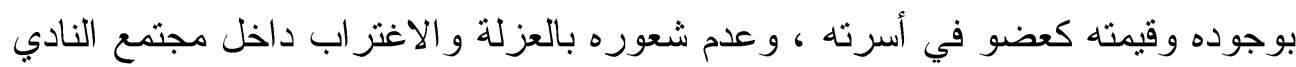

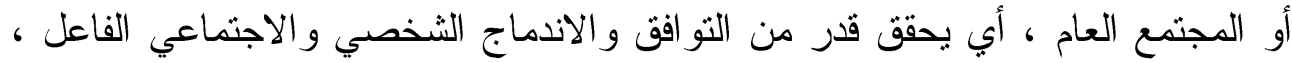
بجانب تو اجده المستمر في المدرسة وفي الصف الدراسي مع زميله من الأسوياء ، و أن يستقبد مثلكه مثل باقي الأسوياء من كافة الخدمات التزبوية و التثقفية و الأكاديمية

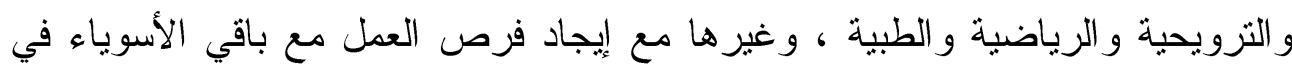

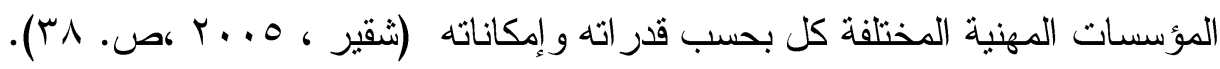

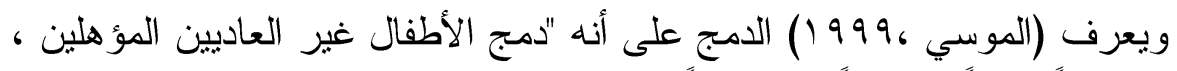

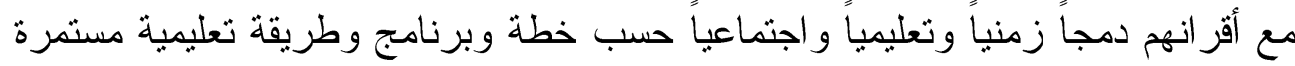
حسب حاجة كل طفل على حدة". ويعرفه ستينباكو ستينبالك (Stainbac\&Stainbac, 1990) على أنه " التحاق

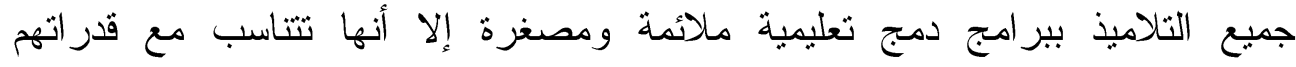

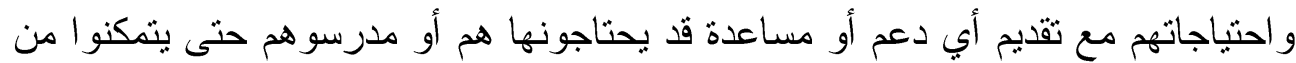

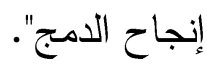

ويؤكد آلين وشوارتز ( Allen \& Schwartz, 2001 ) على أهمية البدء بالدمج

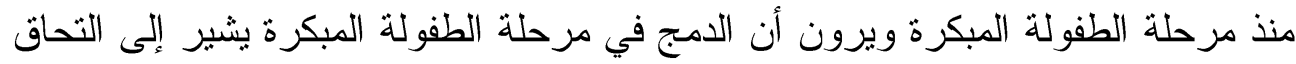

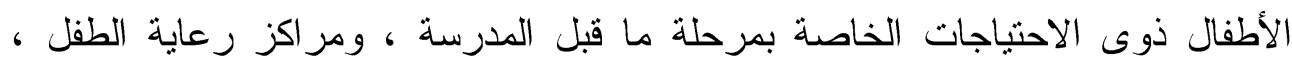

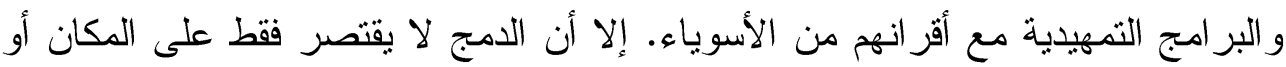

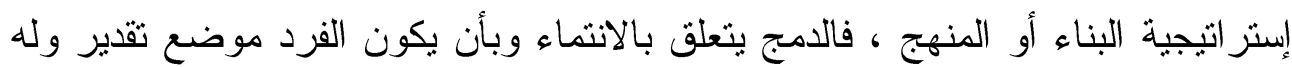

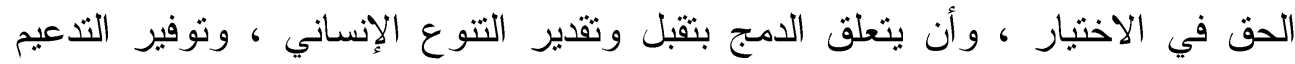

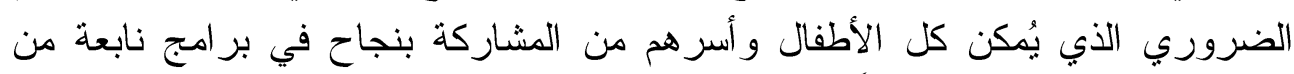

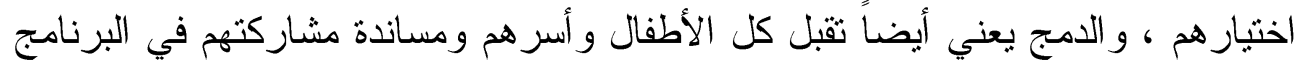

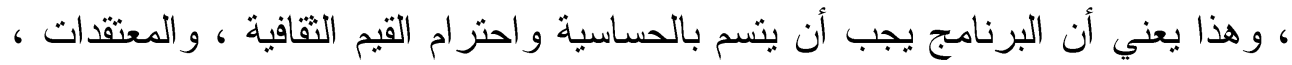
و الممارسات. 
ويرى الشخص(997 199، ص. V^) أن تحقيق أهداف الدمج يتطلب العديد منا لاجر اءات رغم أنها تختلف من بلا إلى آخرويمكن تحديد بعض العناصر الأساسية منها

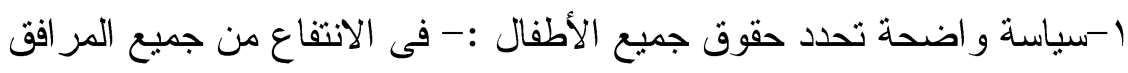

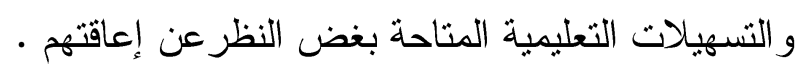

r- التز ام السلطات المدرسية بدعم عملية إدماج المعاقين وتعزيزها وتوفير المساعدات اللازمة للمعلم.

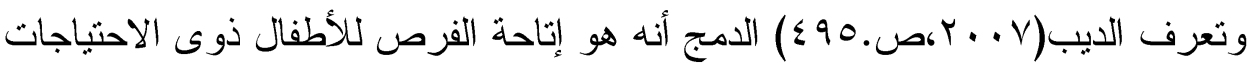

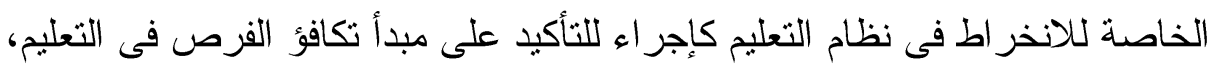

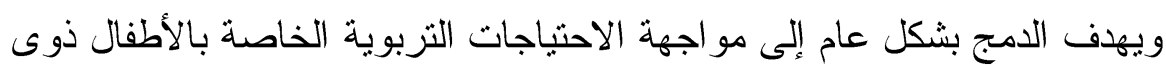

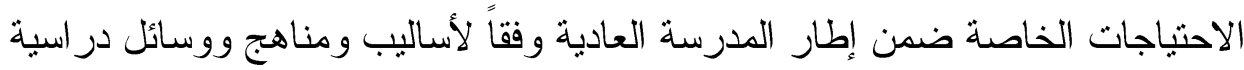

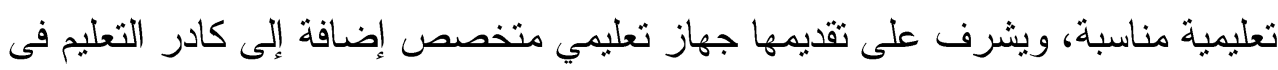

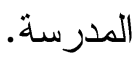

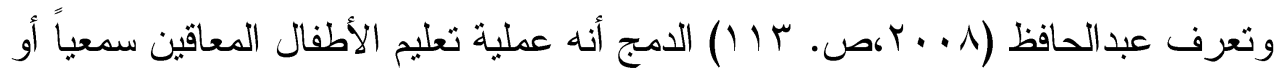

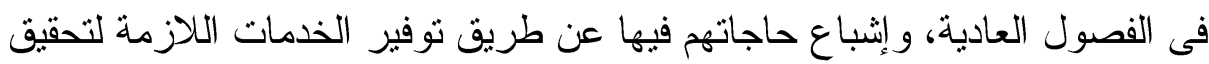

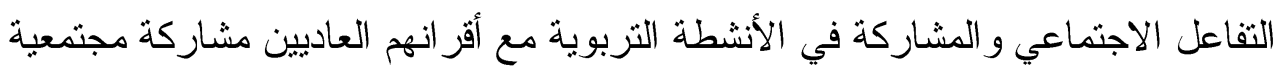

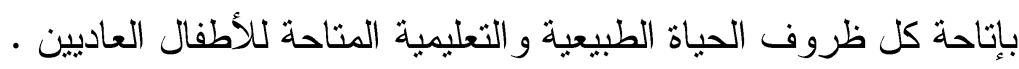
ويوضح الباحثان أن الدمج هو عدم عزل الأشخاص ذوى الإعاقة عن أقرانهم

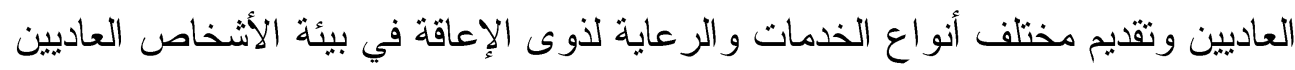

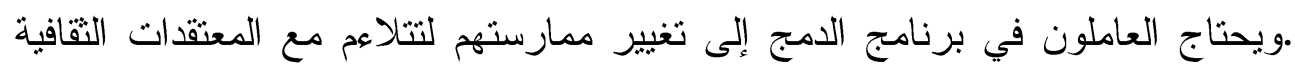

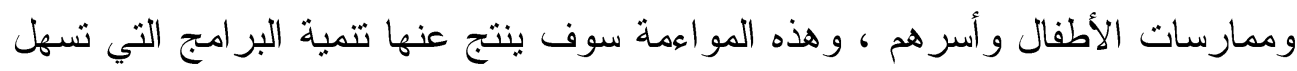
الانتماء و الارتقاء بالنمو المثالي للطفل.

\section{Full Inclusion هفهوم الدهمج الشاهل}

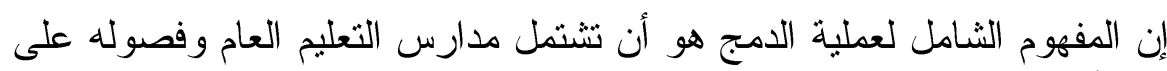

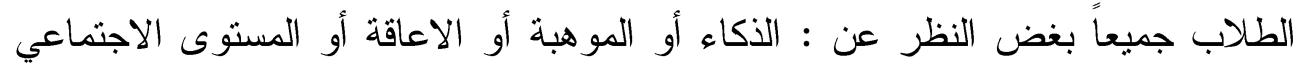

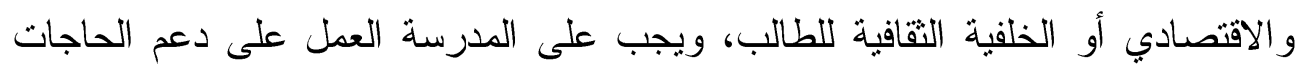

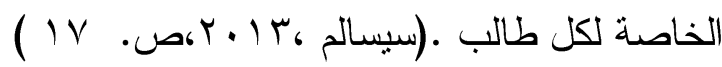


يتم ذلك النوع من الدمج بوضع الأطفال ذوي الاحتباجات الخاصة في فصول

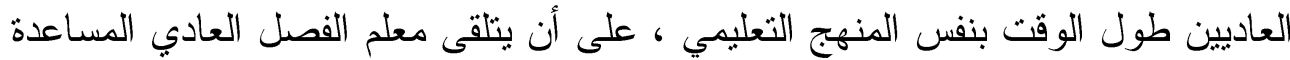

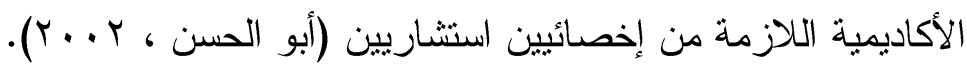

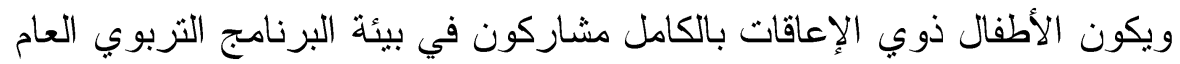

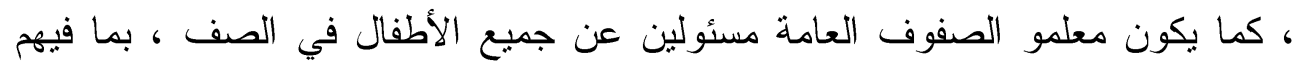

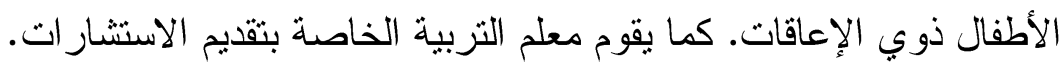

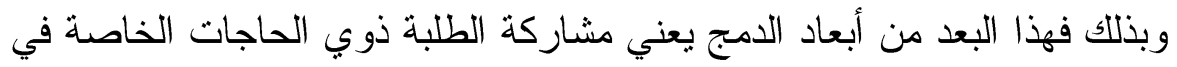

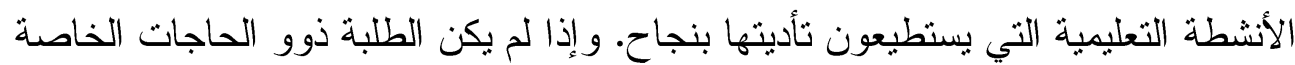

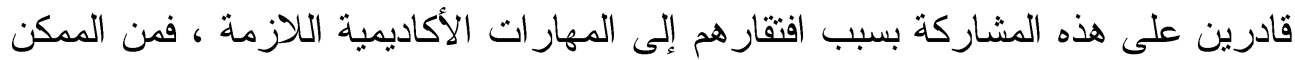

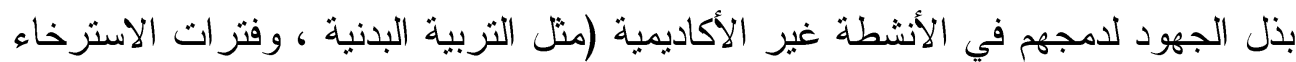

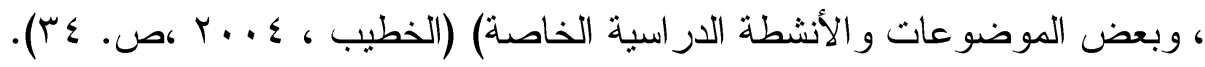
وقد ظهرت مصطلحات الدمج الثامل Inclusion للإشارة إلى عملية تعليم الطلاب المعوقين ضمن بر امج التزبية العامة ، حيث يشير الدمج الثامل إلى مشاركة الجميع ضمن بيئة تربوية عامة داعمة تشتمل على خدمات تربوية مناسبة ، و وعلى أثكال

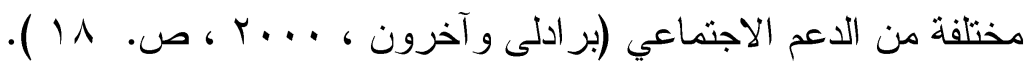

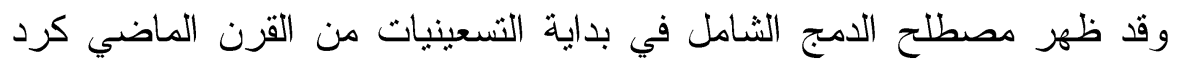
فعل لضآلة العائد من ور اء نظام توحيد المسار في بعض المدارس النظامبة للأطفال في

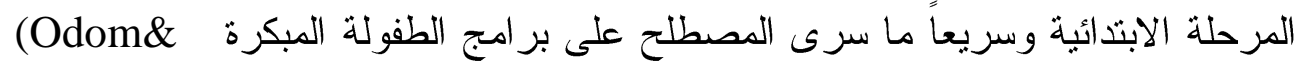
Diamond, 1998 ,p 5)

و تقوم فلسفة الدمج الثامل على ما يعرف بفلسفة عدم الرفض

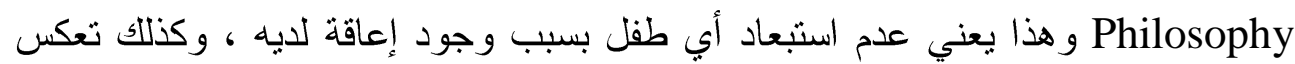

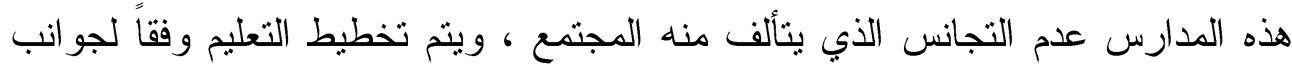

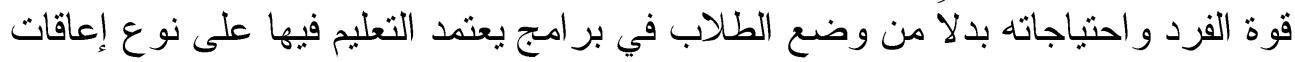

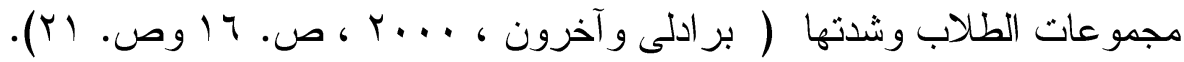

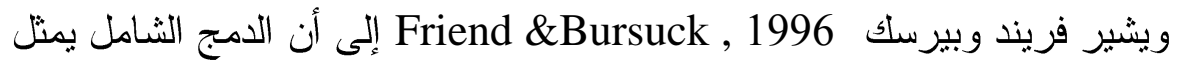

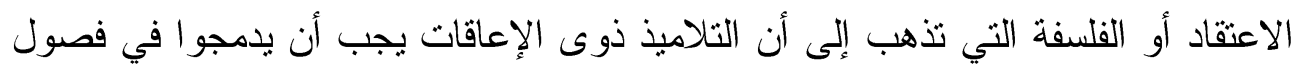
التزبية العامة سو اء تمكنو ا أم لم يتمكنو ا من تحقيق المستويات المنهجية التقليدية.

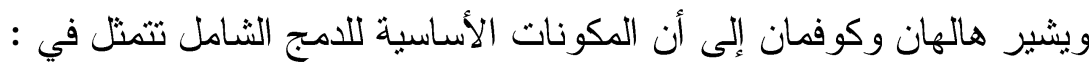
1- أن جميع الطلاب يلتحقون بالمدرسة التي كانو ا يلتحقون بها إذا لم تكن لديهم إعاقة. 
r- وجود نسبة مئوية من الطلاب المعوقين في أب مدرسة.

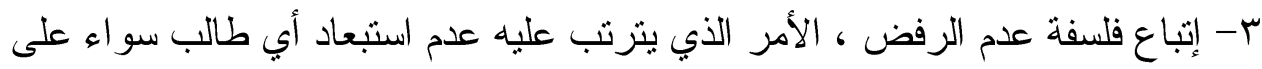
أساس نوع أو درجة إعاقته. ع- أن تكون المدارس و أماكن التزبية النظامية مناسبة لجميع الأعمار و المستويات ، و ألا يكون فيها مكان لفصول التزبية الخاصة.

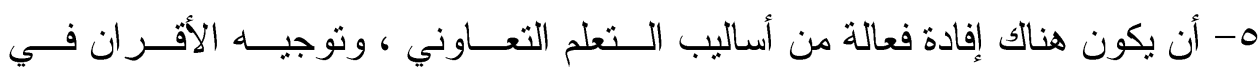
الممارسات المنهجية بالمدرسة.

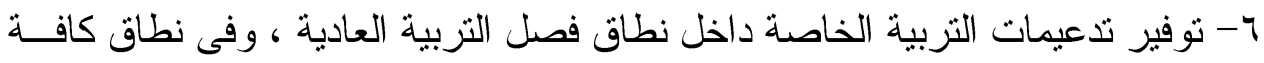
بيئات الامج الأخرى ( Hallahan\& Kauffman , 1994 ,p 53 ). ويعرف الباحثان الامهج الثامل بأنه هو قبول الطفل بالروضة(المدرسة) مهما كانت حالته

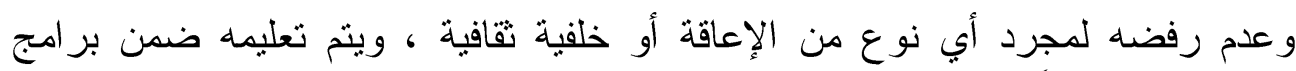
التزبية العامة وفقاً لجو انب قوة الطفل ونو واحنياجاته.

\section{(r) شروط دهج الأطفال ذوى الاحتياجات الخاصة :}

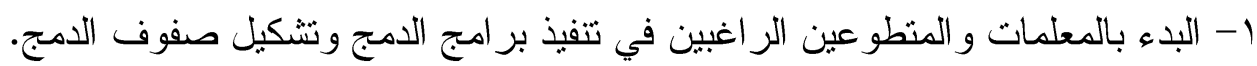

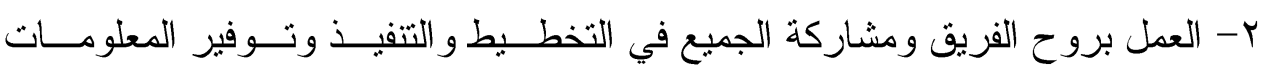

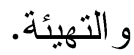
r- ك- ت تقفيذ البرامج التنريبية. ع- توفير مصادر الدعم وتدبير الأمور الإجر ائية ، والدمج تدريجياً و إتباع منحنى و اقعي في التغيير.

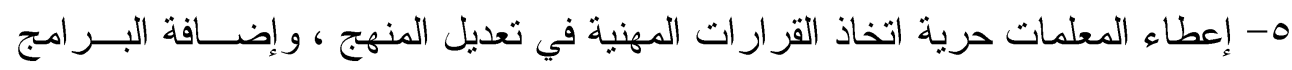

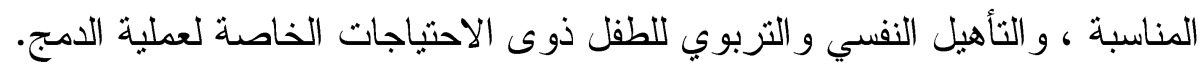

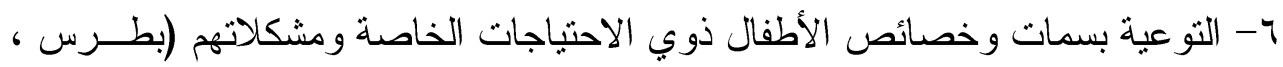

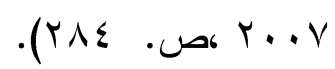

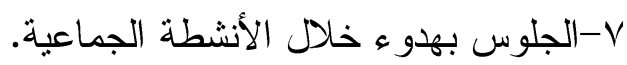

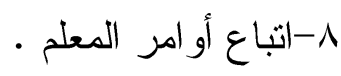

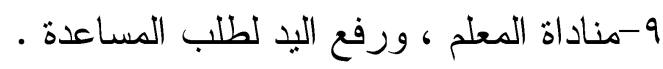

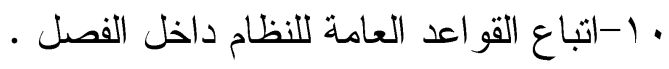


1) ا-ان يستطيع الطالب الاعتماد على نفسه في قضاء الحاجة دون مساعدة الغير •

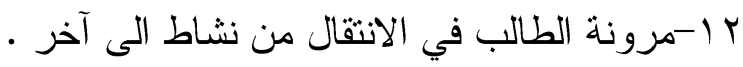

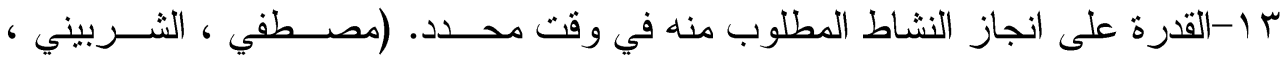
$(r \cdot) \leq$

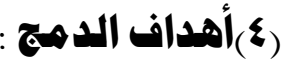

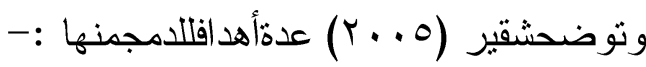

- تقديم كافة الخدمات الطلابية للطلاب المعاقين بمو اقعهم وبجو ار سكنهم.

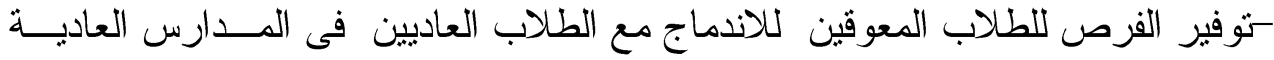
ومساعدتهم علىتطوير قدر اتهم التعليمبة.

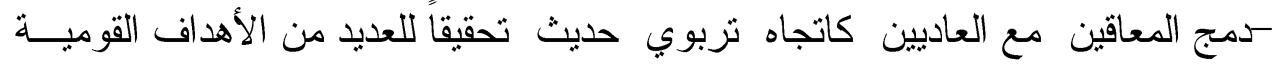

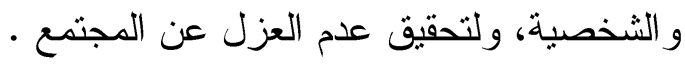

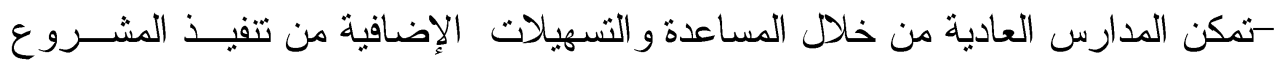

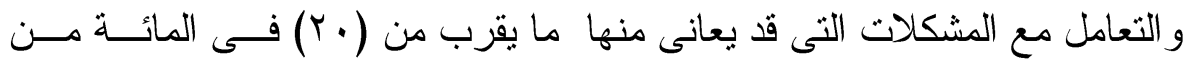
الطلاب فى المدارس. -التخفيف عن مدارس الأقسام الداخلية ومدارس المدن الكبرى. -خفض التكاليف الخاصة بمدارس المعوقين.

-محاولة تغيير المدارس العادية وتشجيعها لتبنى أساليب لأكثر تطور أ. -الدمج حق لكل معاق كأى طفل غير معاق فى الاستفادة من اقتصاديات المجنمع.

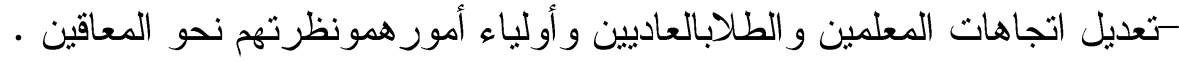

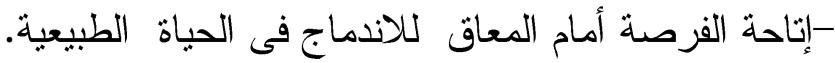
-التأكد من قدرة المعاقين على متابعة الدر اسة في أقرب مدرسة محلية إلى جانب أقر انهم العاديين.

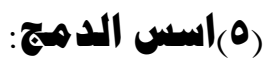

-الأساس القانوني : حيث أن التعليم حق لكل فرد يجب أن يوفره المجتمع بغض النظر

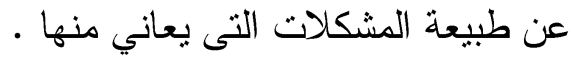
-الأساس الاجتماعي : حيث أنه لا يمكن عزل (المعاق) عن المجتمع الذى يعيش فيه. 
-الأساس الأخلاقي: يعتبر الامج قرارًا مناسباً يمكن من خلاله مواجهة احتياجات ورغبات المعاق داخل المجتمع و احتر ام إنسانيته أو لاً ثم احتياجاته الخاصنة ثنانياً. وينطلقون في ذلك من أن مفهوم الدمج في جوهرة مفهوم اجتماعي أخلاقي نابع

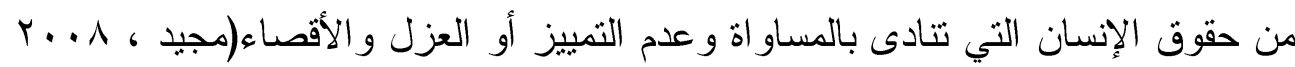

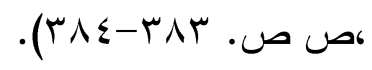

\section{(1) ايمابيات الدهمج: (1)}

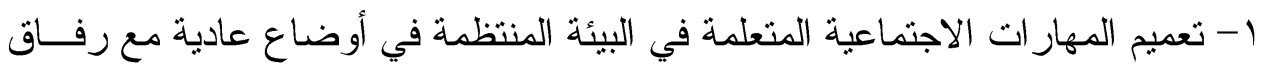
من نفس العمر ، وتعلم مهار ات اجتماعية جديدة.

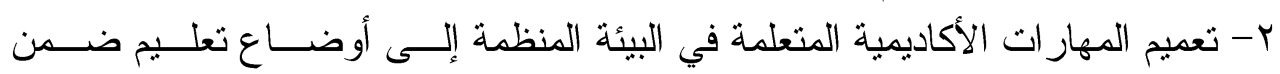

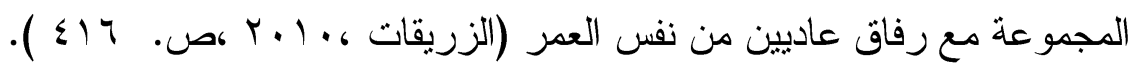

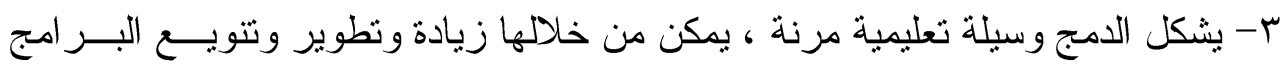
التزبوية المقدمة للتلاميذ المعوقين. ع - اكتساب خبر ات و اقعية متتو عة من خلال تعاملهم مع مشكلات مجتمعية وتفاعلهم مع أقر انهم العاديين. ه- كما يوفر الدمج فرص التقاعل بين الطلاب مما يكسر بينهم حاجز التميز ، ويســاعد

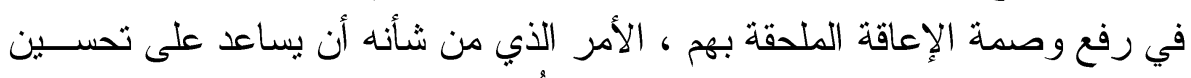

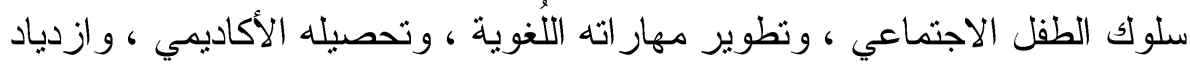

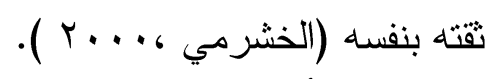

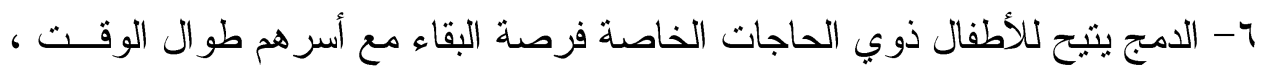

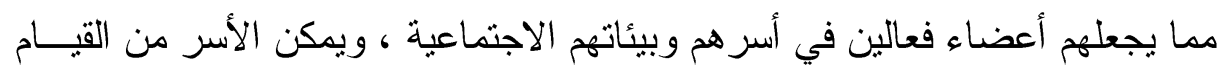

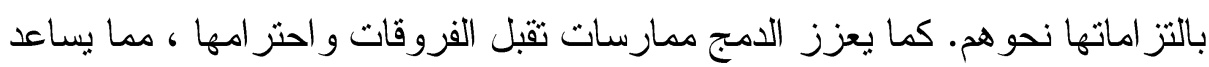

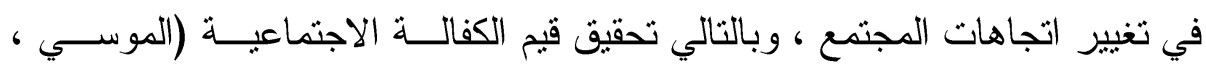
.$(1999$

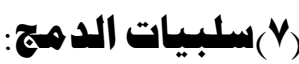

* لا يتمتع المعلمون و المسئولون في مجال التعليم العام بالمهار ات الأساسـية لممارســـة مهامهم التدريسية في ظل نظام الدمج بفاعلية. 
* قد يكون النظام مصدر أ لقلق آباء الأطفال العاديين ، خوفاً مــن محاكــاتهم لتصــرفات

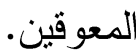

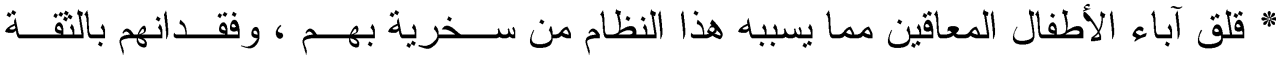
بأنفسهم نتيجة لقصور قدر اتهم على متابعة الدروس مع أقر انهم العاديين.

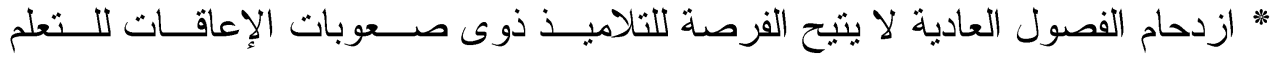

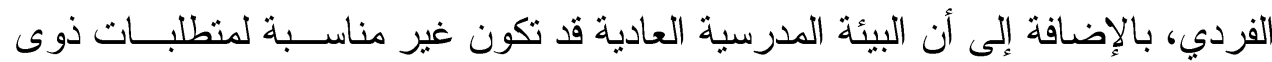

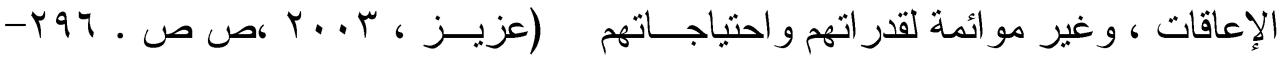

\section{الصعوبات التي تواجه الدهمج :(^)}

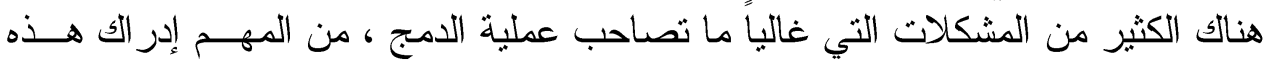

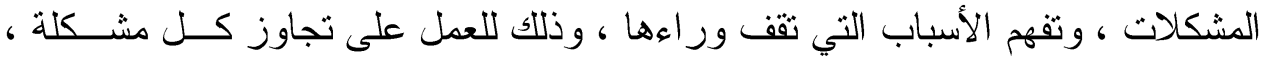

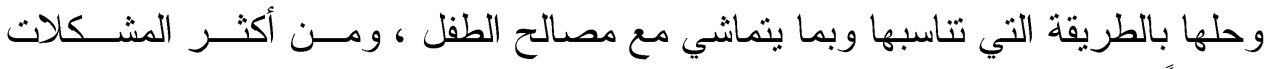

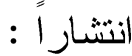

ا-عدم قدرة بعض الأطفال المعاقين على الوصول إلى المدرسة بأنفسه بسبب الإعاقة أو

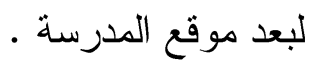

r-رفض المدارس العادية قبول الأطفال المعاقين أو بعض أنو اع الإعاقات خشــية عـــدم

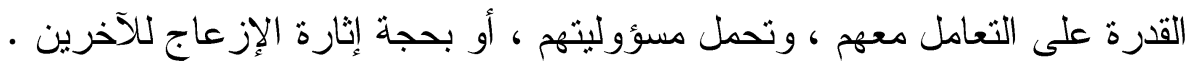

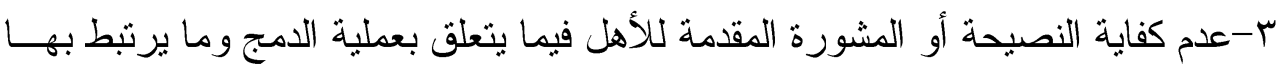

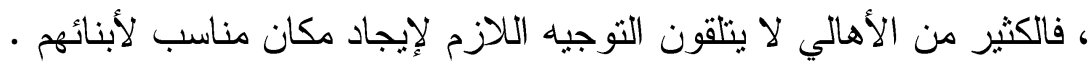

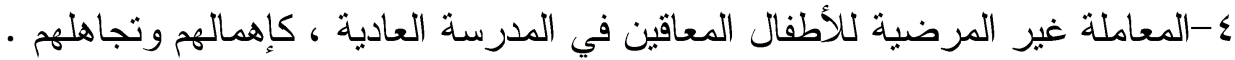

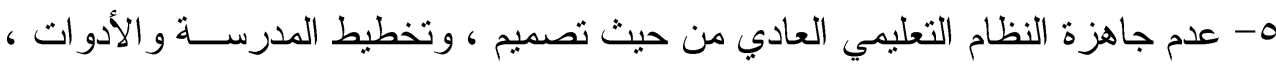

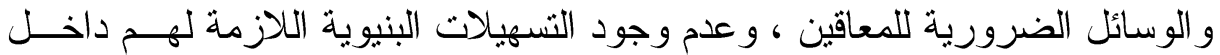
المدرسة .

צ- عدم توفر معرفة كافية لدى المدرسين حول كيفية التعامل و التكييـــ مـــع الأطفــال - المعاقين V-إساءة بعض الأطفال العاديين السلوك نجو الأطفال المعاقين في المدرسة ، مثل ضربهم

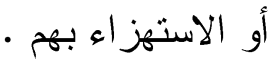




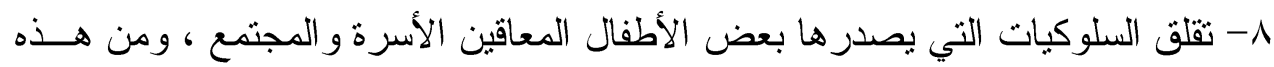

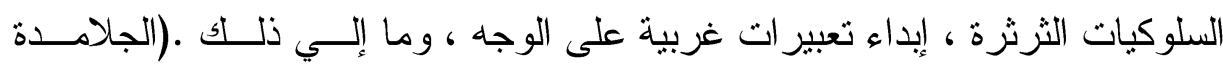

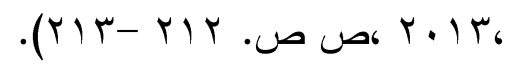

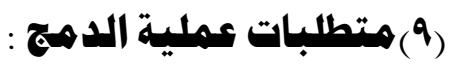

نجد أن عملية دمج الأطفال ذوى الاحتياجات الخاصة لها العديد من المنطلبـات

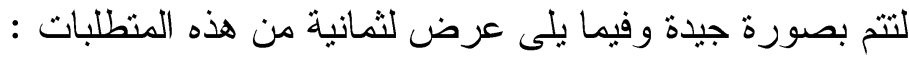

(1) التعرف على الاحتياجات التعليمية للأطفال :

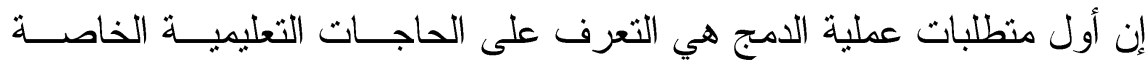

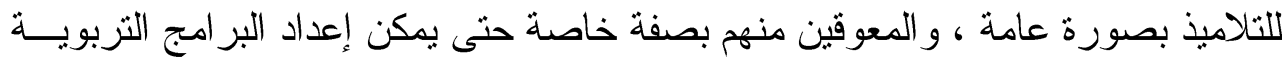

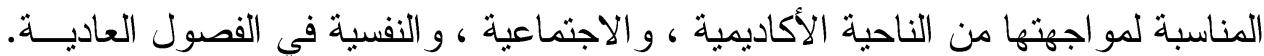

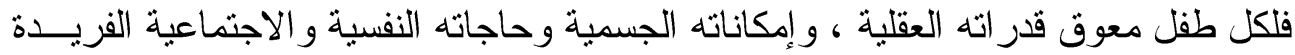

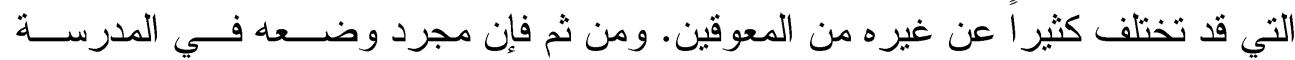

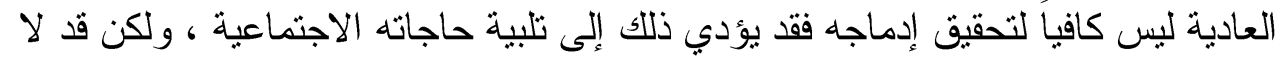

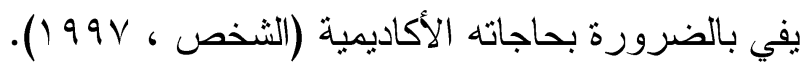

\section{(Y) (إعداد القائمين على التربية}

ومن خصائص مشرو عات الدمج الناجحة : - أنها وفرث القيادات الإدارية.

- عملت على تحسين ، ونجاح التو اصل ، و والمشاركة بين أفر اد المشروع. - وفرت مصادر كافية من كل من الكو ادر و التكنولوجيا لون المستخدمة.

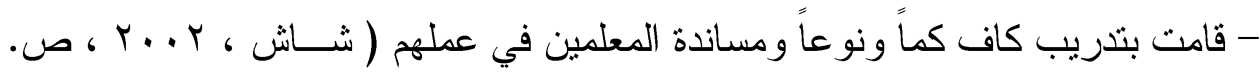

$$
\text { إعداد المعلمين : }
$$

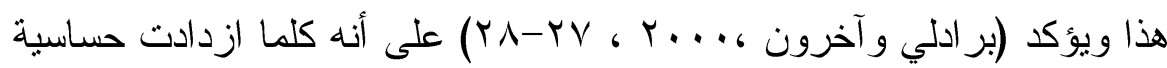

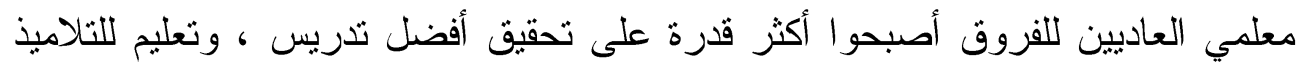

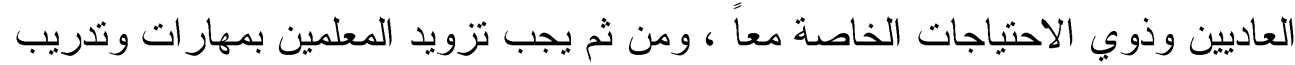
محدد لمساعدنهم في التهيؤ لعملية الدمج. 
( ) إعداد المناهج و البرامج التربوية :

من متطلبات الدمج ضرورة إعداد المناهج الدراسية والبرامج الترجية التربوية المناسبة

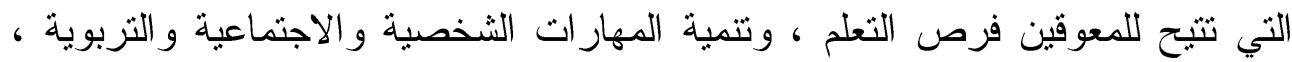

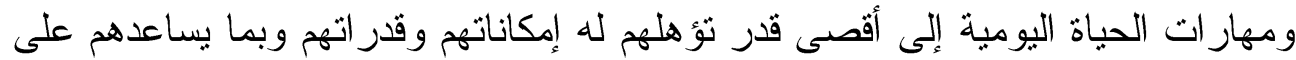

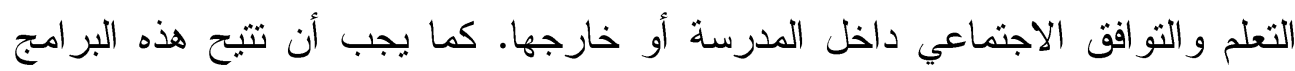

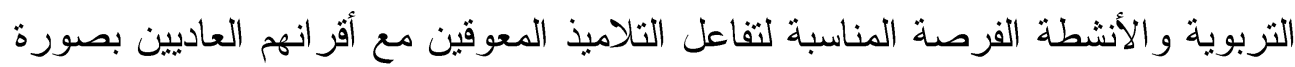

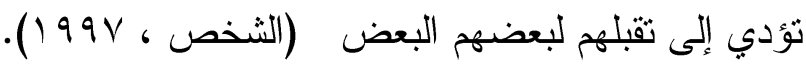

$$
\text { إعداد وتهيئة الأسر : (0) }
$$

من الأهمية بمكان اشتر الك الأسر في تحديد فلسفة مدرسة الدمج ، بالإضافة إلى في الإنى

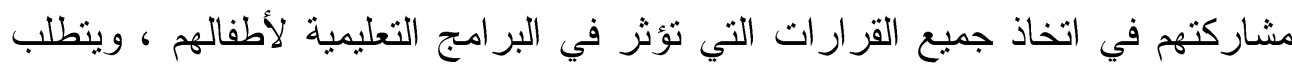

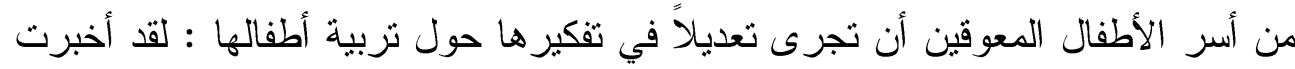

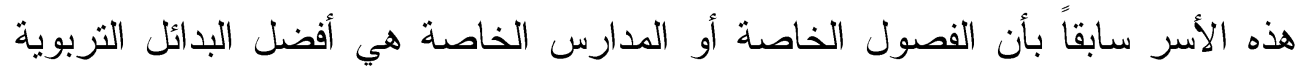

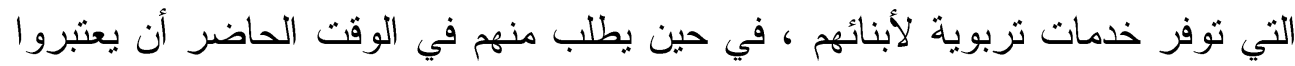

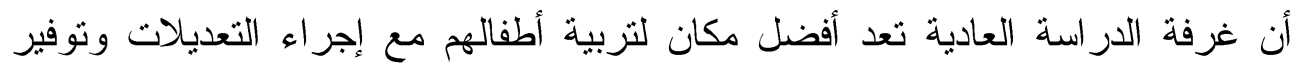

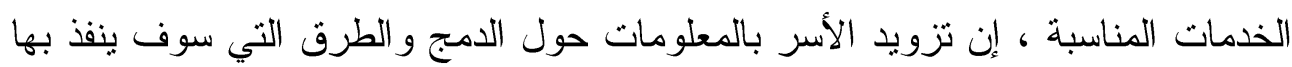

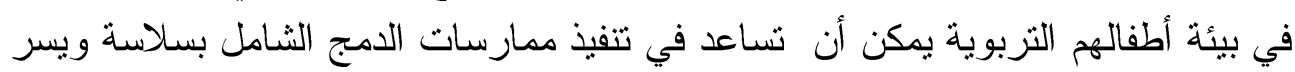

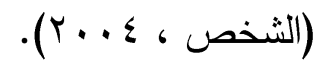

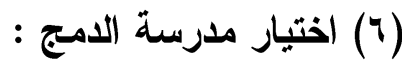

تتطلب عملية الدمج اختيار إحدى مدارس الحي أو المنطقة التعليمية لتكون مركزاً

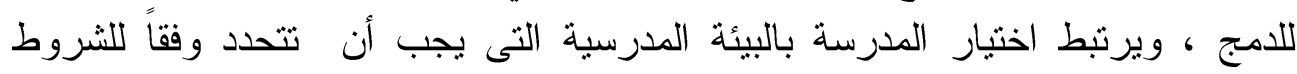
التالية:

- تهيئة جو وفلسفة مدرسية قائمة على الديمقر اطية و المساو اة. - الحصول على دعم و أفكار جميع من سيقومون بالمشاركة.

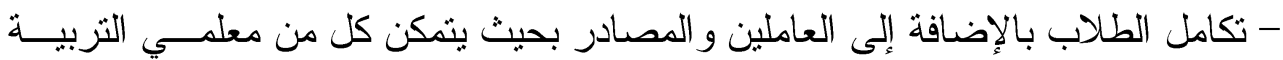
الخاصة و العامة من العمل معاً.

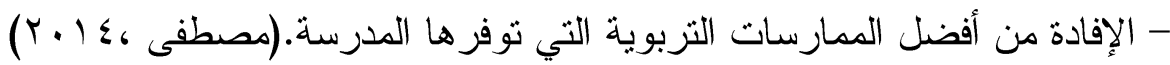


: إعداد وتهيئة التلاميذ (V)

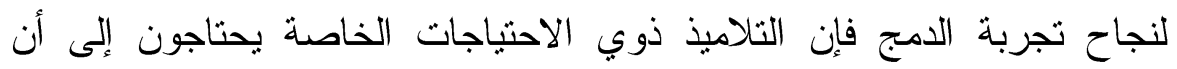

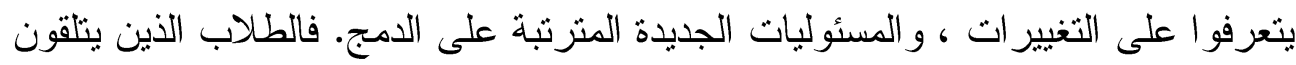

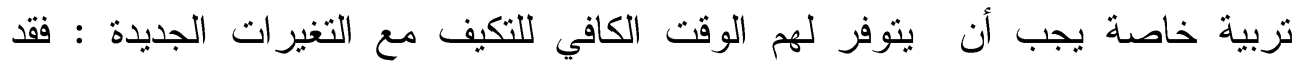

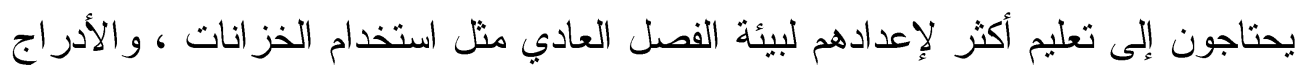

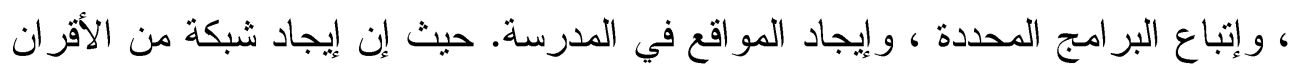

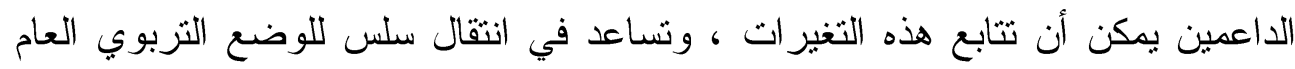

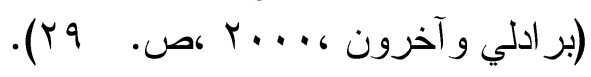

كما بحتاجون إلى أن يتعرفوا على الأماكن التي سيدرسون بها مع زمانئهم

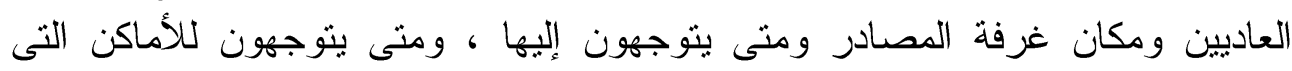

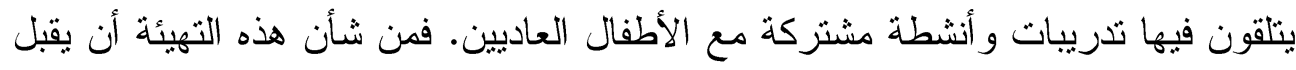

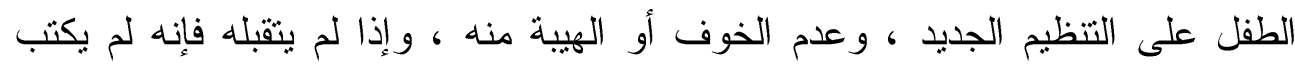
لامجه مع الأطفال العاديين النجاح.

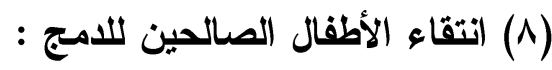

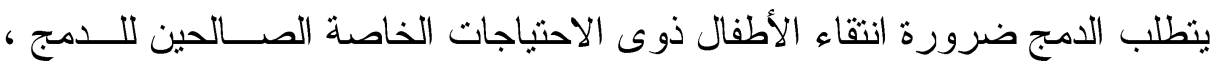

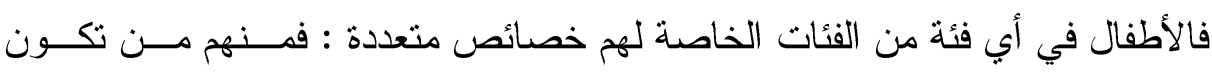

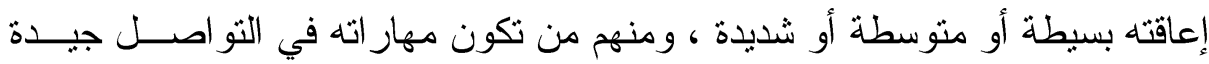

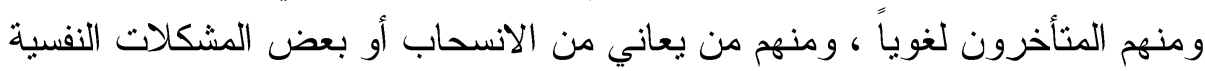

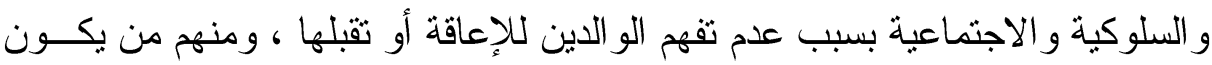

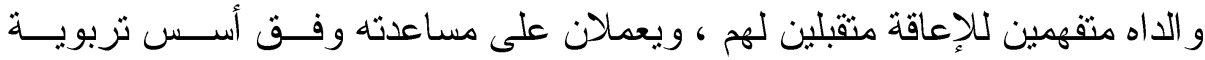

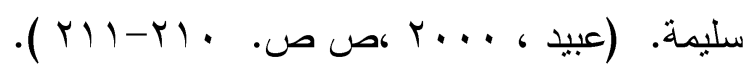

المعور الثاني : الكفايات العامة الضرورية لمعلمي الصفوف العادية لدمج الأطفــال ذوى

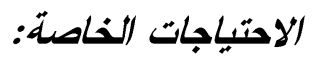

لقد أثنار (الخطيب ،و الحديدي، 991 (19) الى عدد من الكفايات الضرورية للمعلم العادي من أجل دمج الأطفال المعوقين: 1-القدرة على ملاحظة السلوك وتسجيله في المو اقف الصعبة. 
r-القدرة على العمل كعضو فاعل مع الفريق المتعدد التخصصات. ب-المعرفة حول فئات الأطفال ذوى الحاجات الخاصة و أسبابها و أبعادها التربويةالنفسية.

ع -معرفة خصائص النمو الطبيعي ، و أساليب تطوير البرامج التربوية الفردية. ه-القدرة على تقسير أهم المعلومات الواردة في التقارير الطبية و النفسية -التزبوية حول الأطفال.

4-بناء علاقات عمل مناسبة مع الجمعيات و المؤسسات ذات العلاقة بفئات الإعاقة.

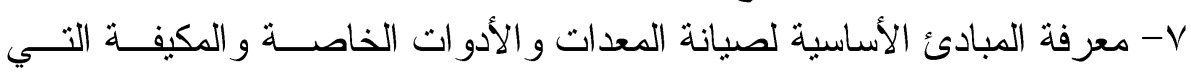
يستخدمها الأطفال ذوو الإعاقة.

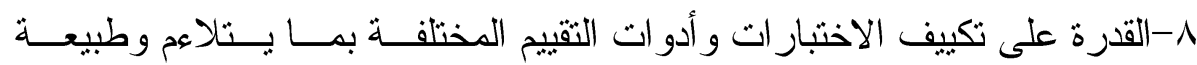
الاحتياجات الخاصة.

9-القدرة على بناء علاقات عمل مفيدة مع أير الأطفال المعاقين.

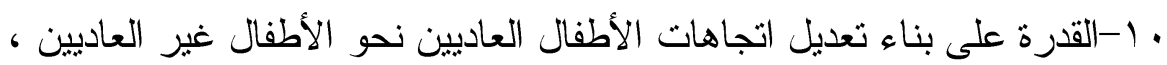

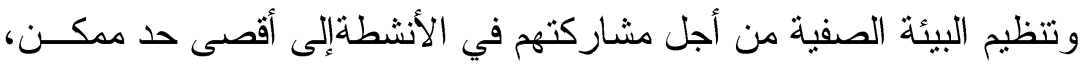
و المعرفة بأساليب تعديل السلوك.

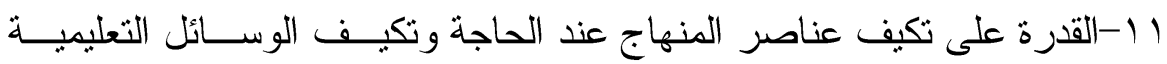
وطبيعة حاجات المعاقين.

المهور الثالث: (1)خصائص مدارس الدمج الثامل (مدرسة المستقبل) ما يلي : 1- التحاق جميع الطلاب في مدرسة الحي.

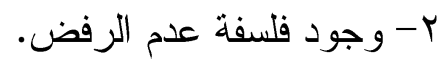

r- الطلاب المعوقون في المدرسة يحتلون نسبة من أولئك المتو اجدين في المجتمع العام.

ب- تقديم مدير و احد هو المسؤول عن جميع البرامج في تلاك المدرسة. ع- الاتصال المستمر بين الطلاب المعوقين و العاديين. ه- وضع الطلاب في صفوف مناسبة لأعمار هم.

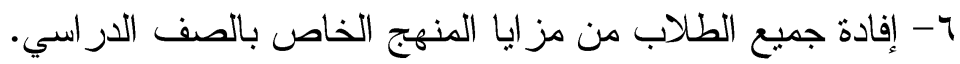
- V وجود دليل للتدريس الفردي و التعاوني وتدريس الأقران. ᄉ- تقديم الخدمات المساندة في بيئة التذريس الطبيعية. 9- الاشتر الك في الخبر ات و المو اد التعليمية. 
• 1 - وجود دليل للتعاون بين العاملين في المدرسة.

$$
\text { 11 - استخدام نظم الدعم الطبيعية. }
$$

r ا - تشجيع العاملين و الطلاب على احتر ام الفروق الفردية بين الأفر اد.

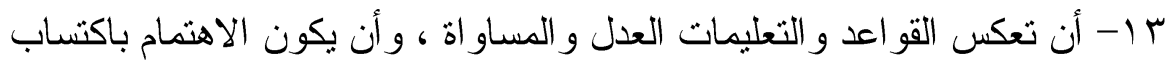

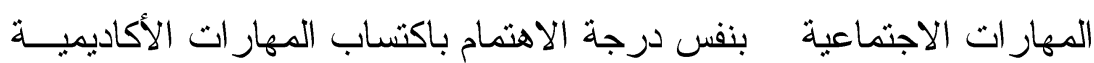

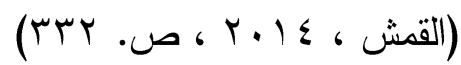

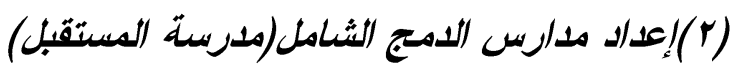

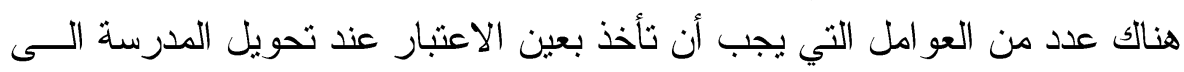

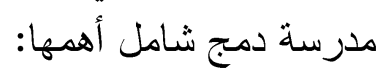

ا-بهيئة وجود فلسفة قائمة على الديمقر اطية و المساو اة.

Y-الحصول على دعم و أفكار جميع من سيقومون باتئ بالمشاركة.

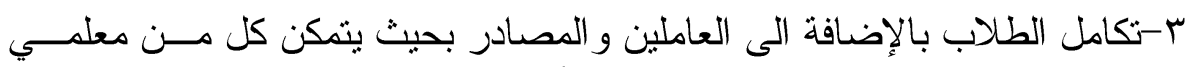

$$
\text { التزبية الخاصة و العامة من العمل معاً. }
$$

ع-الاستفادة من أفضل الممارسات التزبوية التي توفرهاه ها المدرسة.

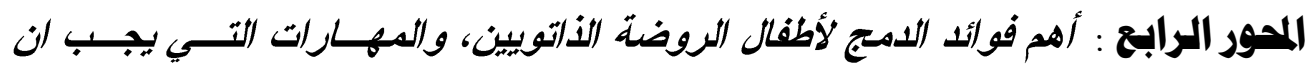

بتعطمها ، وصعوبات دمجهم:

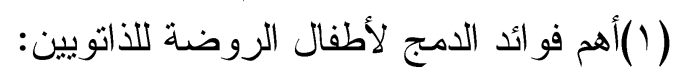

* التخلص من الآثار السلبية لإستر اتيجية نظام العزل.

* التغلب علي قصور الخدمات التزبوية و التأهيلية.

* التغلب علي ارتفاع الكلفة الاقتصادية لإستر اتيجية النظام العربي.

* تأمين الحياة الطبيعية كحق من حقوق الطفل التوحدي.

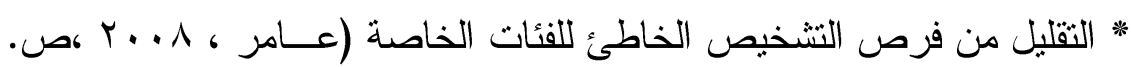

* فرضية التو اصل Contact Hypothesis كان يعتقد أنه عبر دمج الطلبــة ذوي الاحتياجات الخاصة : فإن التو اصل المتز ايد بين هؤلاء الطلبة و أقر انهم الأســـوياء سينمي التقبل ، ويقلل من وصم الأطفال ذوي الحاجات الخاصة.

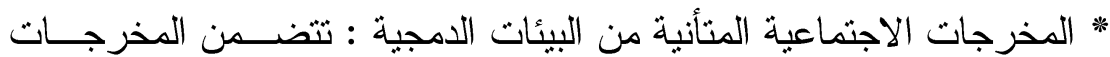

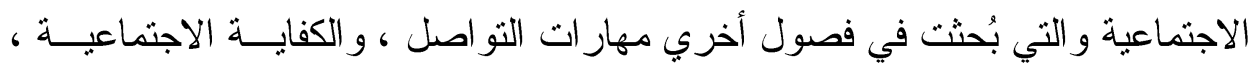


و الصداقات ـ ومن هنا ، تُركز الأغلبية العظمي من الدراسات المتعلقة بثأثبر الصــفوف

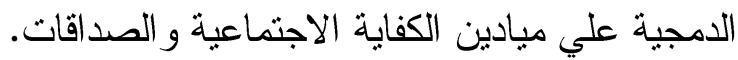

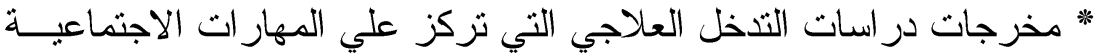

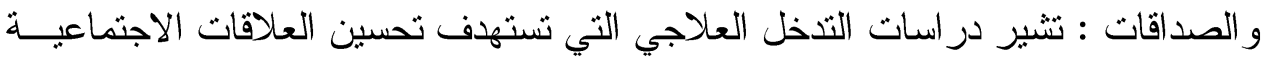

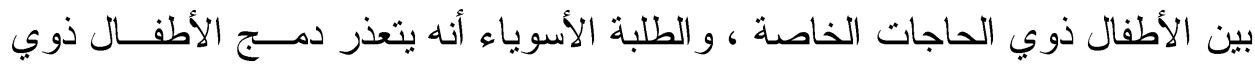

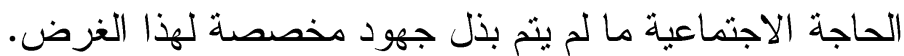

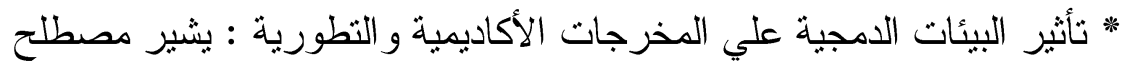

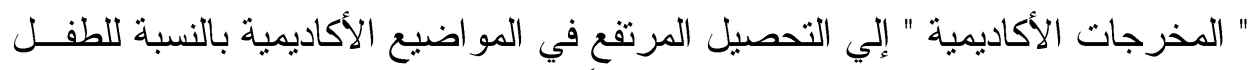

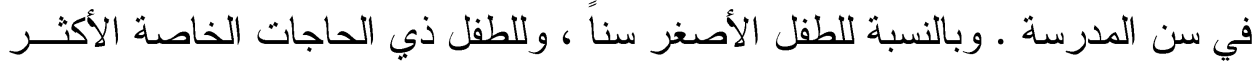

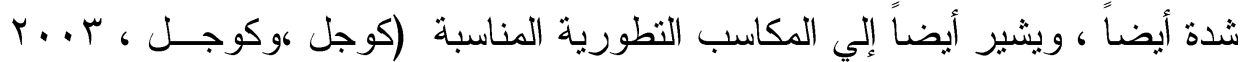

$$
\text { كا ص ص. ro }
$$

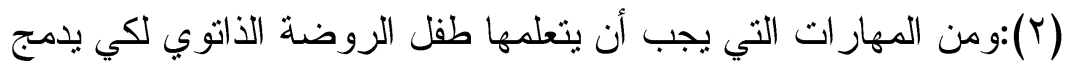

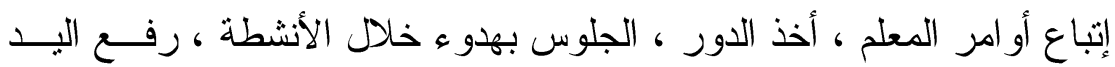

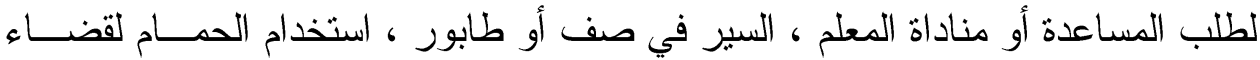

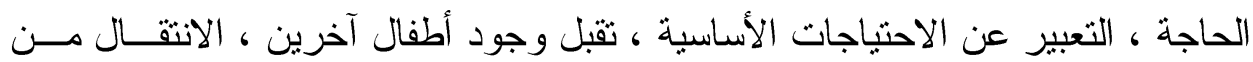

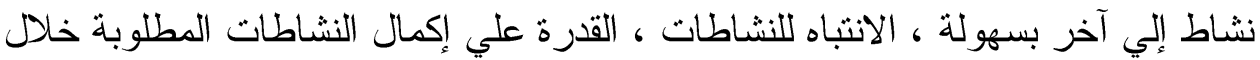

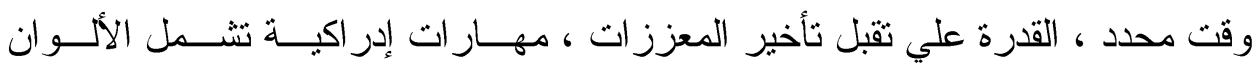

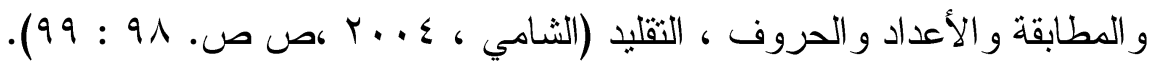

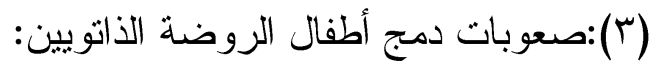

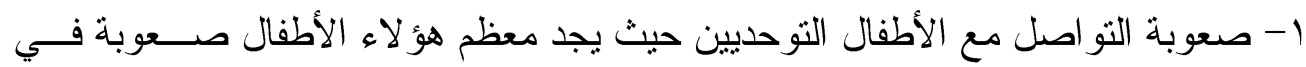

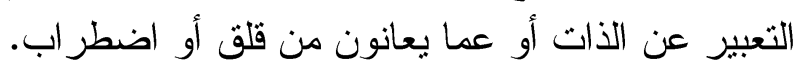

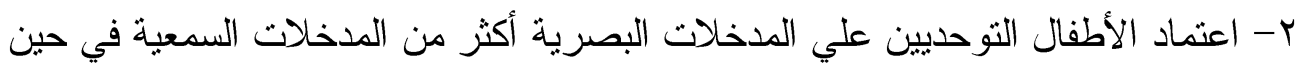

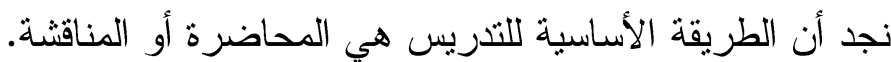

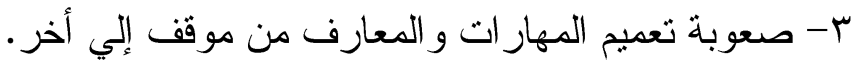

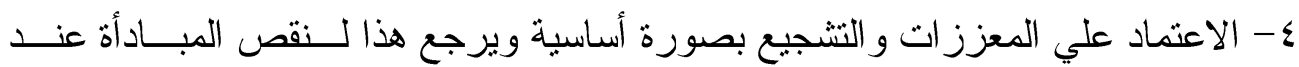
الأطفال التوحديين.

ه- الانتقائية الزائدة للمثير ات وتتضدن الانتباه إلي أجز اء خاصة من المهمة أو الأشياء .

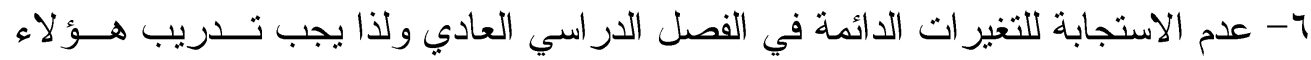

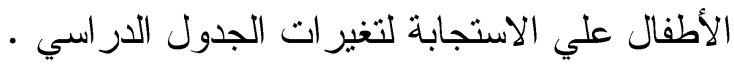




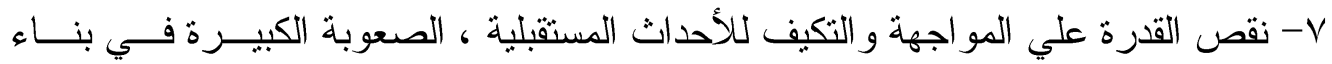

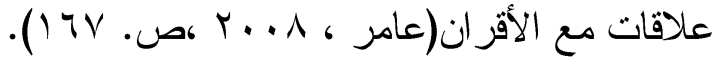

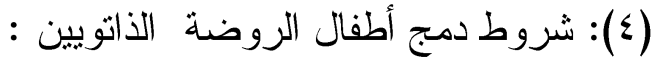

1- يجب أن يكون الدمج مع الأطفال العاديين في مو اد النشاط العام مثل : الرياضة البدنية : الرئية

$$
\text { ، الرسم ، الرحلات و الزيار ات المبدانية. }
$$

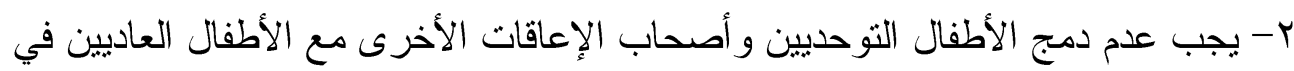
الفصول الدر اسية ، حيث يجب أن يكون لهم فصولهم الخاصة بنفس مدارس التعليم العام

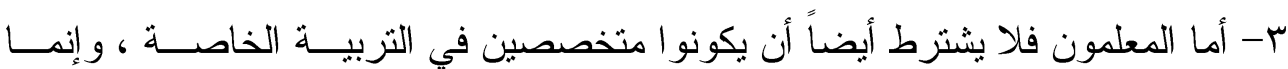

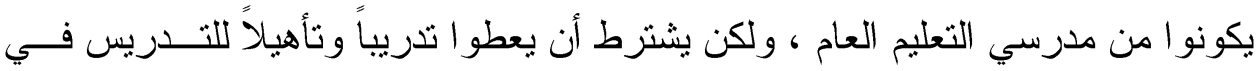

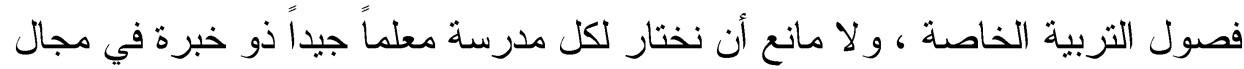

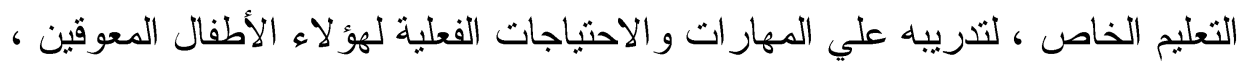
بما فيها أطفال التوحد ، ويجب أن يعطي هؤلاء المتدربون للتدريس في التزبية الخاصة

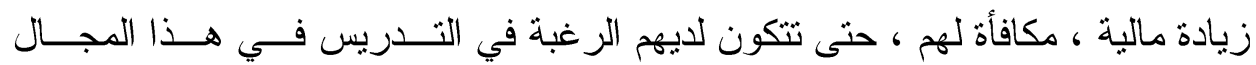

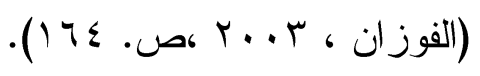




\section{تتائج البحث وتوصيات}

$$
\text { اولا :- نتائج البحث: }
$$

1-أن نظام الذمج الثامل يساعد أطفال الروضة الذاتو يين على تعلم مهار ات تكيف جديــدة من خلال مهار ات التقليد لزملانئهم العاديين.

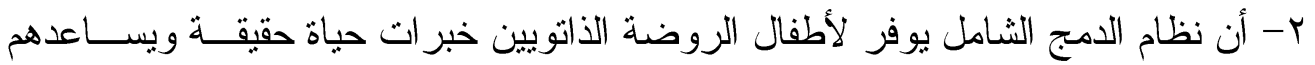
على التفاعل مع أقز انهم وتعلم مهار ات اجتماعية وتو اصلية جديدة.

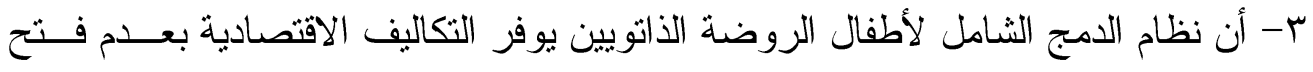
مر اكز للتربية الخاصة ، و المحافظة على مصادر الطفولة المبكرة.

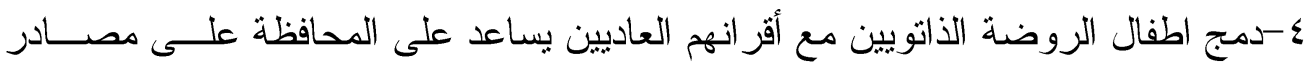

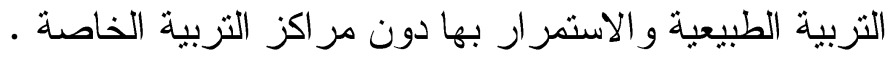

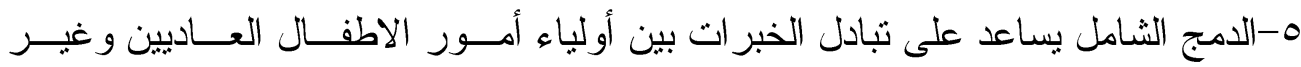
العاديين.

\section{ثانيا :- توصيات البحث :}

ا-تهيئة معلمي الروضة العادية و الاداريين بدورات تدريبية عن سمات الأطفــال الــذاتو بين

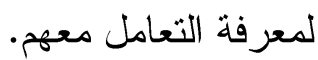

r-ضرورة الاهتمام بإنشاء مؤسسات يتم فيها تطبيق نظام الدمج الثامل.

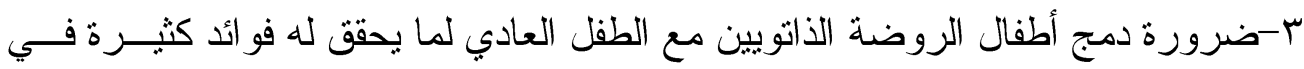

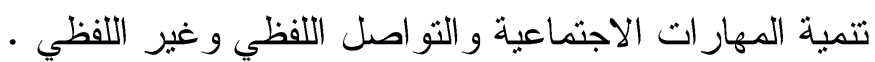

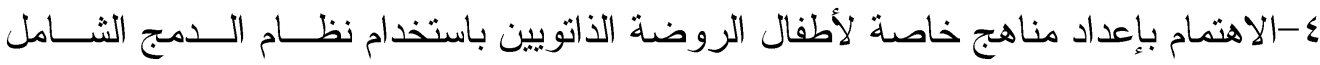
تثماشى مع قدر اتهم و إمكاناتهم. 0-التوسع في نشرة ثقافة الدمج الشامل برياض الثمان الأطفال.

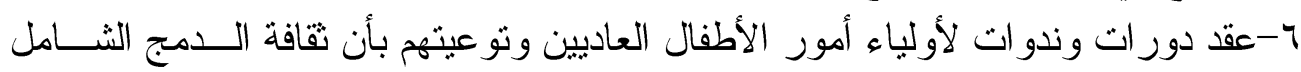

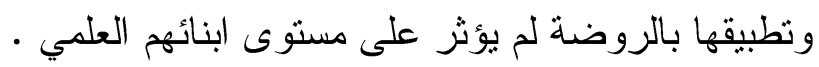




\section{الـــراجـئ}

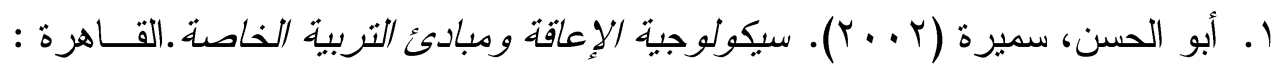
مكتبة حورس للطباعة و النشر.

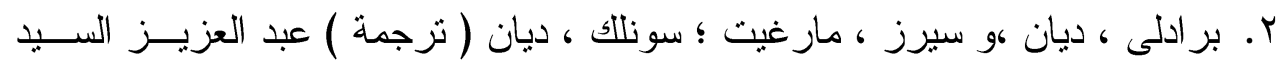

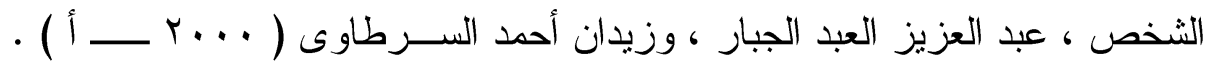

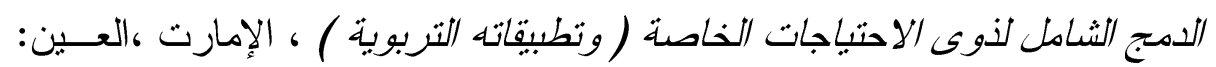

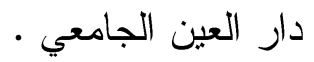

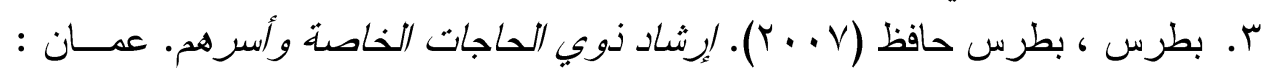

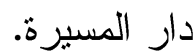

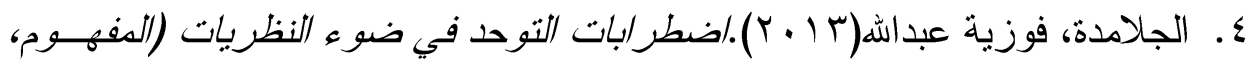

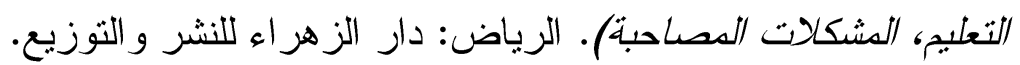

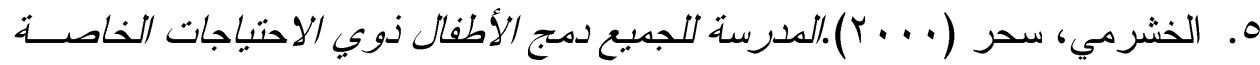

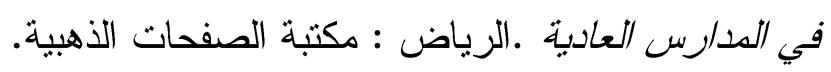

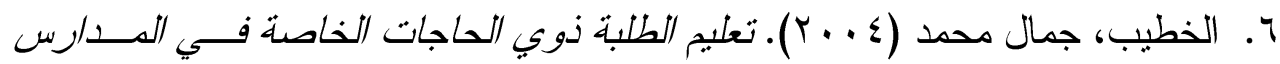

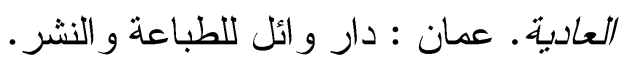

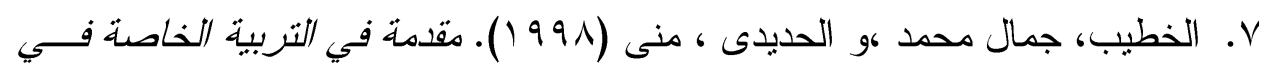

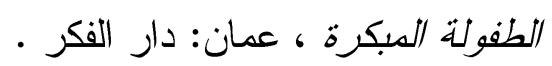

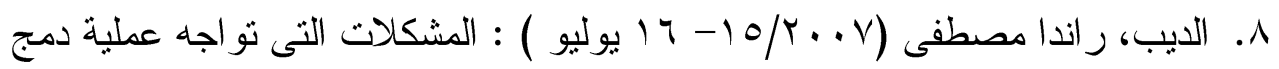
الأطفال ذوي الاحتياجات الخاصة ،المؤتمر العلدي الأول لقسم الصحة النفسية ، كلية

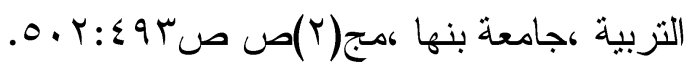

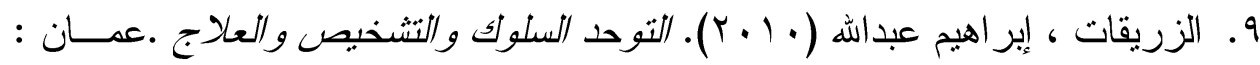

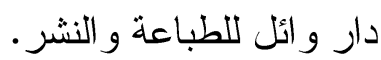

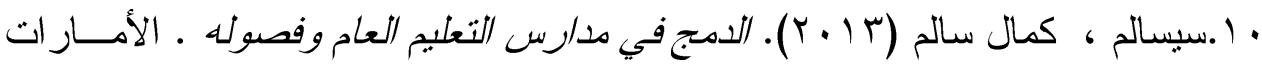

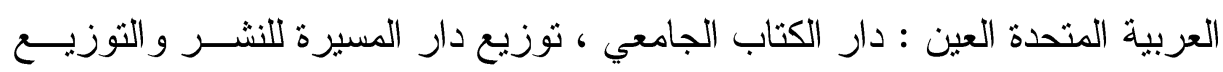

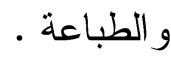

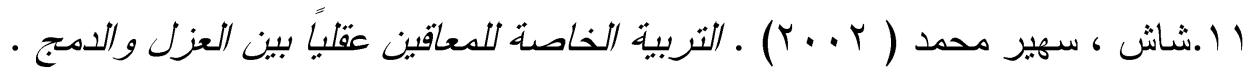
القاهرة : مكتبة زهر اء الشرق. محثر 
r ا ـالثامي ، وفاء علي (ع . . ץ). علاج التوحد ـ الجمعية الخيرية النسوية .جدة:مركز جدة للتوحد.

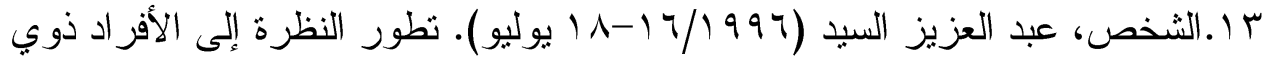

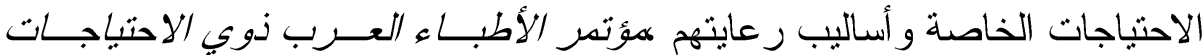

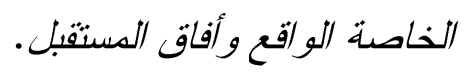

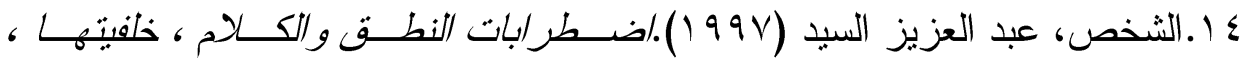

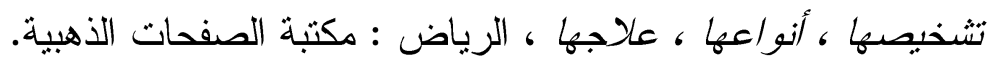

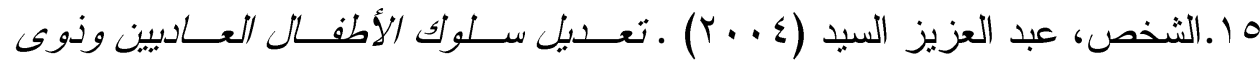
الاحتباجات الخاصة. القاهرة : مركز الفتح للطباعة.

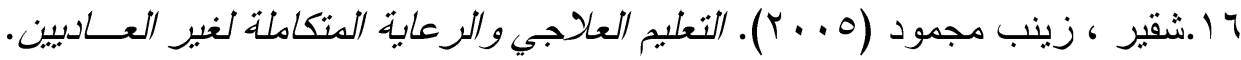
القاهرة : مكتبة النهضة المصرية.

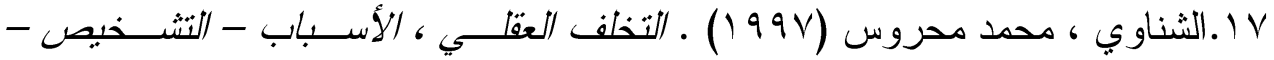

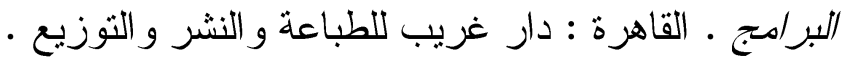

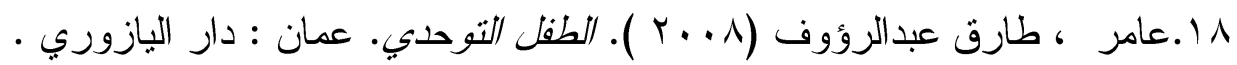

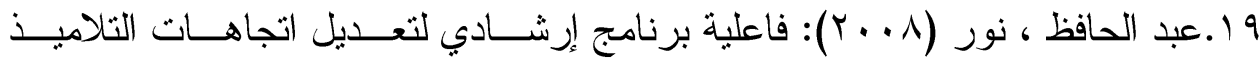

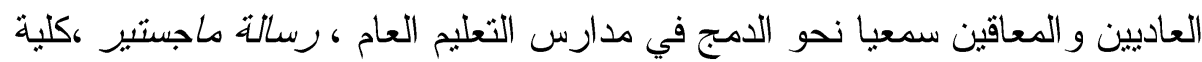
التزبية ،جامعة الزقازيق

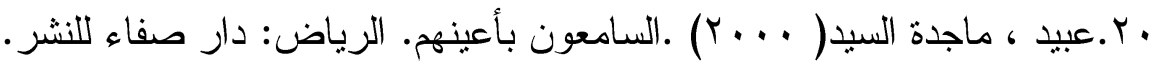

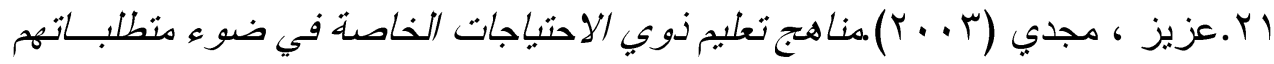
الإنسانية والاجتماعية والدعرفية. القاهرة : مكتبة الأنجلو المصرية.

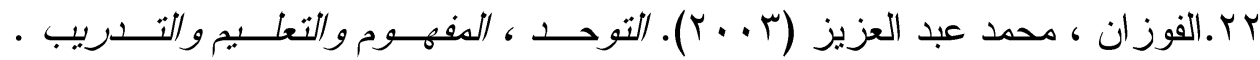
الرياض : دار عالم الكتب.

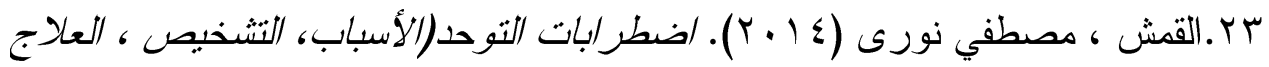

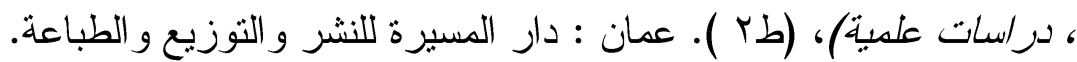

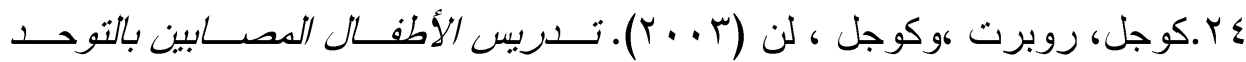

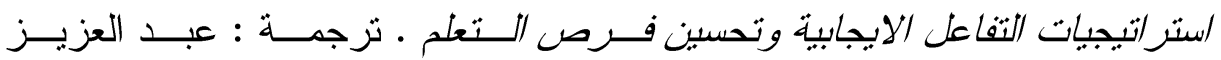
السرطاوي ، و ائل أبو جودة ، أيمن خشان. دبي : دار القلم للنشر و التوزيع.

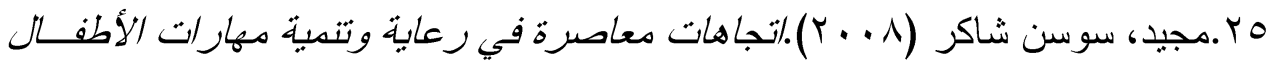

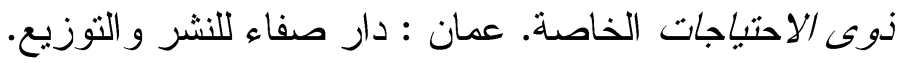




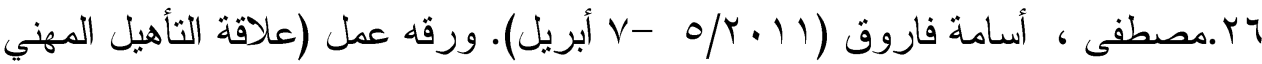

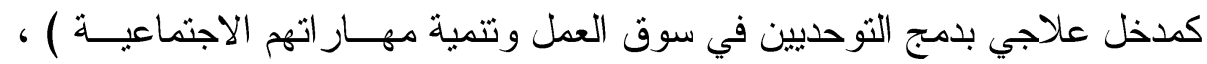

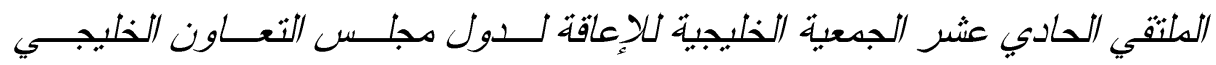

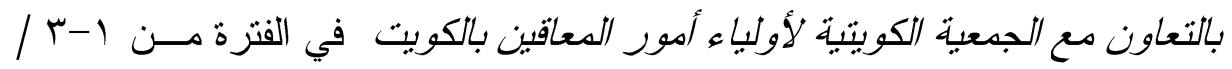
$\rightarrow 1 \leqslant r / 0$

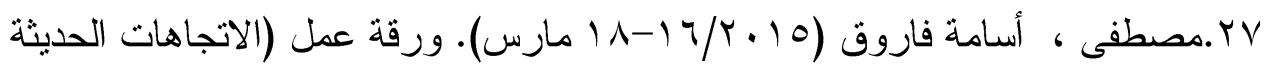

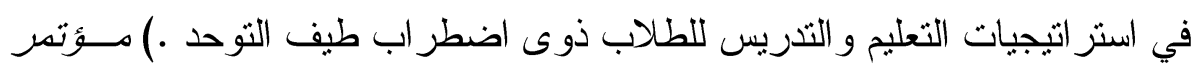

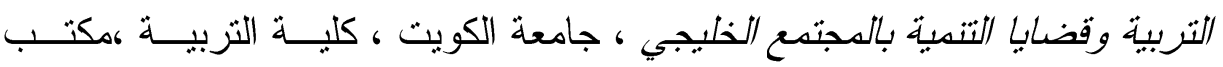

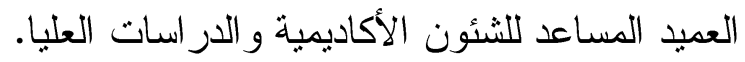

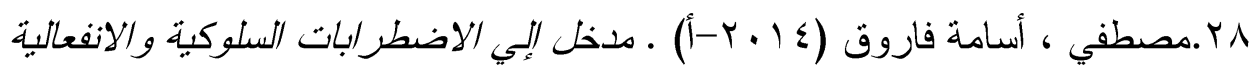

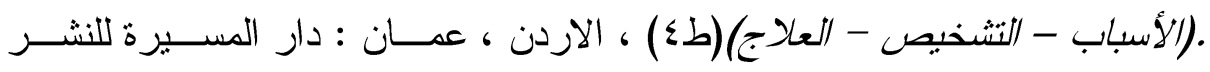
و التوزيع و الطباعة.

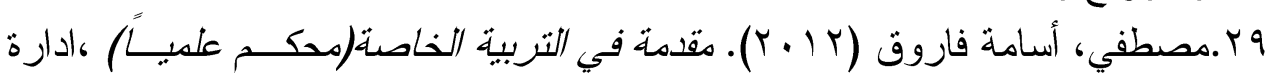

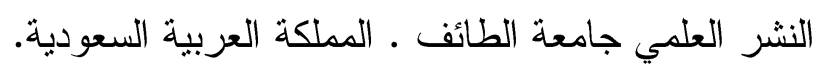

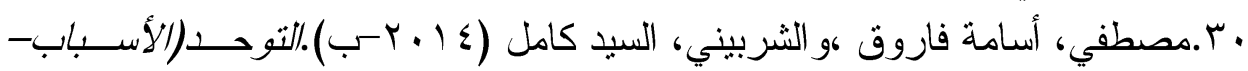
التشخيص - لعلاج)(طب). عمان : دار المسيرة للنشر و التوزيع.

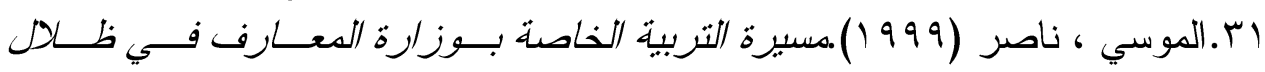

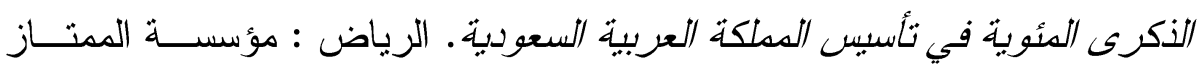
للطباعة و التجليد.

32. Allen K. E. \&Schwartz . I. S. ( 2002 ) : The exceptional child : Inclusion early childhood education, $\mathrm{S}$ Delmar.New York : Appleton . Celtury Croft

33. Hallahan,d\& Kauffman.(199 $\varepsilon)$ Exceptional children : Introduction to Special Education, Boston: Allyn\& Bacon.

34. Odom , S. . \& Diamond, K..( 1998 ). Inclusion of Young Children with Special needs in early child hood education : The research base. Early Childhood Research Quarterly . V. 13 . N. 1 PP(218-223) .

35. Stainbac , W.\&stainbacis . (1990) .facilitating Inclusive schooling : Interde pendent integrated education . Baltimor, MD : Brookes . 


\section{Contemporary to meet the challenges and constraints of the overall integration of kindergarten children with autism}

The study aimed to the importance of early intervention and the need to integrate kindergarten Autism . integrate them into the ranks of public education fully and stand on the comprehensive integration is one of the most important requirements of kindergarten children Autism to prepare the merger is the concept of a social and moral due to lack of isolation from society. And to encourage regular schools that adopt the comprehensive integration of kindergarten children Autism program.

Highlighted the current study looked at what represented the comprehensive integration of kindergarten children Autism of great importance in the provision of educational services provided to them. And it provides those interested with information about the progress of kindergarten Autism and what they need to improve and develop and increase in services to fit with the reality of their own special abilities, so to increase international attention recently merged kindergarten children Autism and achieve their demands through the bodies and institutions concerned. The significance of the study is that it comes in response to developments and developments successive in our world today, and for this they are trying to give an overview of the importance of the comprehensive integration of kindergarten children Autism regular schools with their Normal peers .they have special needs require teaching methods characteristic can not be provided, but specialists in the field of autism . And know the attributes and characteristics of the kindergarten child Autistic has shown the child sensitivities about the stimuli Al_hush (such as certain sounds or certain lights) and without regard to like him for these properties will be the overall integration process is very difficult for both the teacher and the child Autistic, as it would be useless.

The results of the study found that the overall system integration helps kindergartners Autism to learn new adaptive skills through imitation of ordinary skills to their colleagues. It also provides for kindergarten children Autism life experiences of the fact that help them interact with their normal peers and learn new social skills and communication. And it provides economic costs not to open special education centers, and maintain the Early Childhood sources. It also helps to maintain the natural sources of education and continue it without special education centers. And it helps to exchange experiences between the parents of the Normal children and special needs children.

key words: Integration - Autism - kindergarten 